A THESIS SUBMITTED TO

THE GRADUATE SCHOOL OF NATURAL AND APPLIED SCIENCES

$\mathrm{OF}$

MIDDLE EAST TECHNICAL UNIVERSITY

BY

YADİGAR SEYMEN

IN PARTIAL FULFILLMENT OF THE REQUIREMENTS

FOR

THE DEGREE OF MASTER OF SCIENCE

IN

METALLURGICAL AND MATERIALS ENGINEERING

JUNE 2016 

Approval of the thesis:

\section{LARGE STRAIN AND SMALL-SCALE BIAXIAL TESTING OF SHEET METALS}

submitted by YADİGAR SEYMEN in partial fulfillment of the requirements for the degree of Master of Science in Metallurgical and Materials Engineering, Middle East Technical University by

Prof. Dr. Gülbin Dural Ünver

Dean, Graduate School of Natural and Applied Sciences

Prof. Dr. C. Hakan Gür

Head of Department, Metallurgical and Materials Engineering

Assist. Prof. Dr. Mert Efe

Supervisor, Metallurgical and Materials Engineering Dept., METU

\section{Examining Committee Members:}

Prof. Dr. Riza Gürbüz

Metallurgical and Materials Engineering Dept., METU

Assist. Prof. Dr. Mert Efe

Metallurgical and Materials Engineering Dept., METU

Prof. Dr. C. Hakan Gür

Metallurgical and Materials Engineering Dept., METU

Assoc. Prof. Dr. Y. Eren Kalay

Metallurgical and Materials Engineering Dept., METU

Assist. Prof. Dr. Celalettin Karadoğan

Department of Manufacturing Engineering, Atılım University

Date: 27.06.2016 
I hereby declare that all information in this document has been obtained and presented in accordance with academic rules and ethical conduct. I also declare that, as required by these rules and conduct, I have fully cited and referenced all material and results that are not original to this work.

Name, Last Name: YADİGAR, SEYMEN

Signature 


\begin{abstract}
LARGE STRAIN AND SMALL-SCALE BIAXIAL TESTING OF

SHEET METALS
\end{abstract}

\author{
Seymen, Yadigar \\ M. Sc., Department of Metallurgical and Materials Engineering \\ Supervisor: Assist Prof. Dr. Mert Efe
}

June 2016, 64 pages

Small-scale and multi-axial testing of sheet metals, particularly of lightweight alloys and advanced high strength steels (AHSS) are becoming important as these materials exhibit forming behavior sensitive to their unique microstructural features and strain paths. As an alternative to large-scale standard tests, in this study, a novel biaxial tensile test apparatus for miniature cruciform samples is introduced. The compact and portable apparatus includes a custom-built optical microscope and high-resolution digital imaging and correlation equipment for in-plane and in-situ strain measurements at the microstructure scale. The small strain and premature fracture problems common to the cruciform tests are solved by optimizing the sample design and by meticulously controlling the manufacturing steps and surface finish. Strain analyses reveal a key mechanism responsible for large strains and fracture at the center. This mechanism suppresses the local neck formation and allows uniform deformation under equibiaxial conditions until 
fracture. When normalized with the strain hardening exponent of the sample material (Al 6061-T6), the effective strain value before fracture, $\bar{\varepsilon} / \mathrm{n} \sim 3$, surpasses the reported values for similar materials tested by cruciform and standard methods.

Keywords: Biaxial Tension; In-Situ Testing; Cruciform; DIC; Aluminum. 


\title{
ÖZ
}

\section{METAL LEVHALARIN BÜYÜK GERINIMLERDE VE KÜÇÜK ÖLÇEKLERDE İKİ EKSENLİ TESTİ}

\author{
Seymen, Yadigar \\ Yüksek Lisans, Metalurji ve Malzeme Mühendisliği \\ Bölümü Tez Yöneticisi: Yard. Doç. Dr. Mert Efe
}

Haziran 2016, 64 sayfa

Hafif alaşımlar ve gelişmiş çelikler başta olmak üzere metal levhalar, mikroyapısal özelliklerine ve gerinim yönlerine göre şekillendirme davranışı gösterdiğinden, bu malzemelerin küçük ölçekli ve çok eksenli testleri önem kazanmaktadır. Bu çalışmada büyük ölçekli standart testlere alternatif olarak, artı şeklindeki küçük numunelerin kullanıldığı, iki eksenli çekme aparatı geliştirilmiştir. Kompakt ve taşınabilir olan bu aparat, düz bir yüzeyde anlık gerinim ölçümü yapmak için özel bir optik mikroskop ve yüksek çözünürlüklü dijital görüntüleme ekipmanı içermektedir. İki eksenli çekme testlerinde yaygın olarak görülen küçük gerinimler ve erken kopma problemi; numune tasarımı geliştirilerek, üretim basamakları ve numune yüzeyi kontrol edilerek çözülmüştür. Gerinim analizleri, numune merkezindeki büyük gerinimler ve kırılmaya neden olan bir mekanizma ortaya çıkarmıştır. Bu mekanizma, numune üzerinde bölgesel boyun vermeyi engellemekte ve kopmaya kadar iki eksenli çekme koşulu altında deformasyona imkan vermektedir. 
Numune malzemesi olan Al 6061 T6 alaşımının gerinim sertleşme katsayısı ile test sonrası elde edilen etkin gerinim değerleri normalize edildiğinde bu değerin $(\varepsilon 7 \mathrm{n}=3)$, bu malzemenin hem iki eksenli hem de diğer standart testlerde elde edilen değerlerini aştı̆̆ gözlemlenmiştir.

Anahtar kelimeler: Eş Eksenli Çekme; Yerinde Deney; Artı Biçimli Numune; Dijital Görüntü İlişkilendirme; Alüminyum. 
To My Precious Family... 


\section{ACKNOWLEDGMENTS}

This work was supported both by TÜBİTAK - 2232 fellowship program for returning scientists to Turkey under the grant agreement \#114C039 and by European Commission's Research Executive Agency's Marie Curie Actions - Career Integration Grant (FP7-PEOPLE-2013-CIG) with grant agreement \#631774. Additionally, the journal article with the same title was utilized in this thesis.

I am indebted to my advisor Assist. Prof. Dr. Mert Efe for his faith, support, encouragement and valuable suggestions all the way from the beginning to the end. Also, I would like to thank him for shaping my academic background with his endless academic experience. I would never complete my thesis without his guidance.

I am grateful to all the people that I have known at the Department of Metallurgical and Materials Engineering, METU for the contributions. I specially thank to my pretty friends, Burçin Kaygusuz, Gözde Yıldırım and Ezgi Onur Şahin, for their invaluable support and friendship in last three years of my life. Moreover, I appreciate to my labmates, Berkay Bayramin, Kıvanç Alkan, Kübra Atik and Baran Güler, for always being goodhumored and helpful. I want to thank Mine Kalkanc1, Burcu Miser and Berke Pişkin who have been answered all my questions patiently. Besides, my wholehearted and special thanks goes to Cihan Özyayla for entering my life and giving a magic touch. Life is beautiful with you.

Last but not least, I owe a depth to my father İskender Selim Seymen, my mother Zuhal Seymen and my brother Veli Seymen for their never ending love, encouragement and trust throughout all my life. This thesis and all my other gains would not have been possible without my family. 


\section{TABLE OF CONTENTS}

ABSTRACT

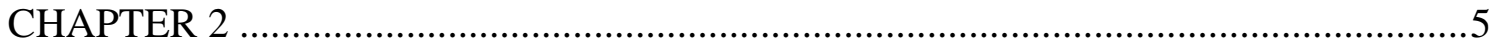

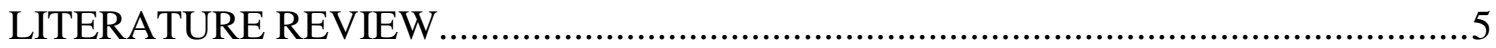

2.1. Formability Behavior of Lightweight Alloys and Advanced High Strength

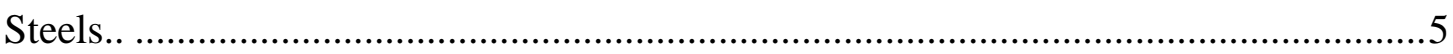

2.2. Introduction to Formability Testing of Sheet Metals ..................................... 8

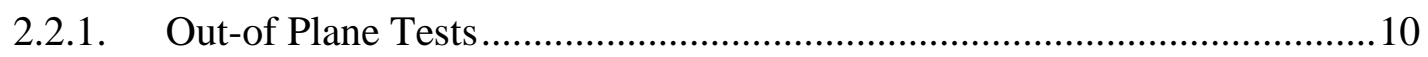

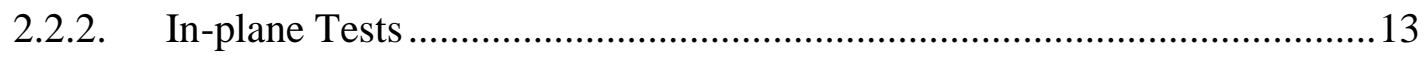

2.2.3. Comparison of Formability Tests at the Microstructure Scale ................. 18

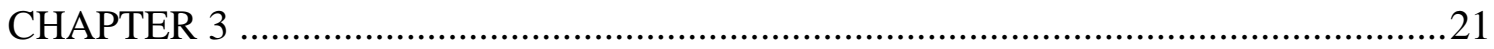

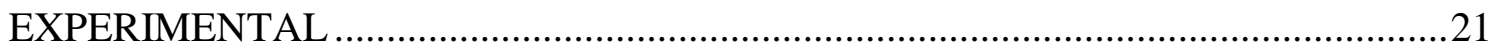

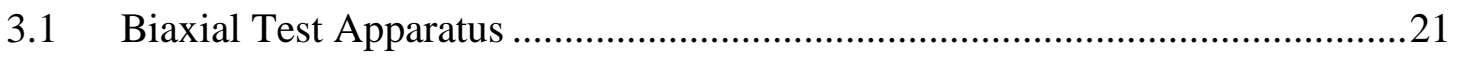

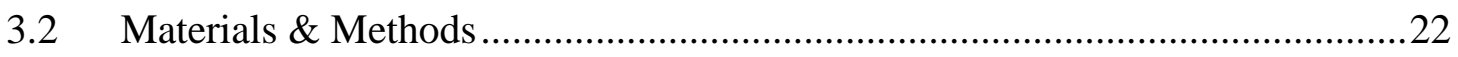

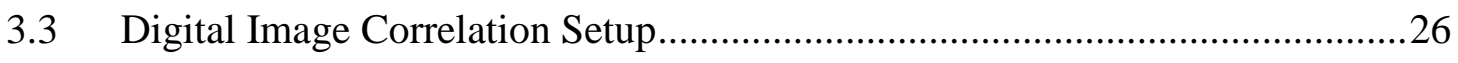

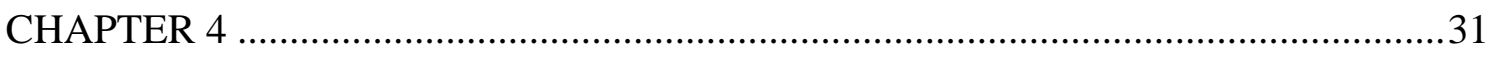

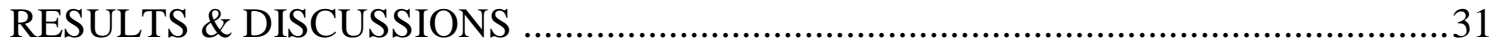




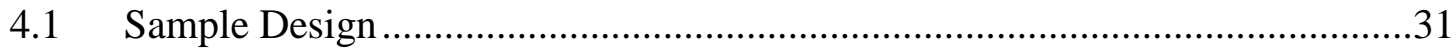

4.2 Controlling the Fracture Behavior by Pit Design and Manufacturing..............36

4.3 Obtaining Large Strains and Fracture at the Center .......................................39

4.4 Comparison with other Multi-Axial Tests ................................................46

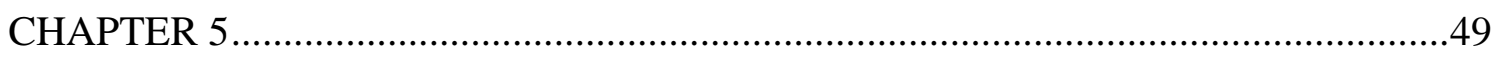

CONCLUSION \& FUTURE RECOMMENDATIONS ...........................................49

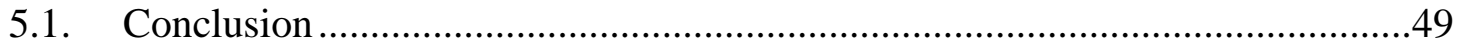

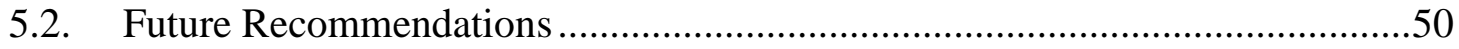

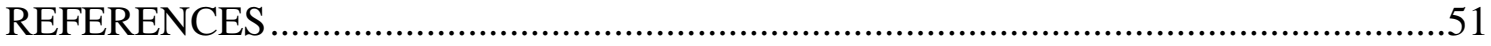

SPRINGER LICENSE TERMS AND CONDITIONS ..........................................59 


\section{LIST OF TABLES}

\section{TABLES}

Table 2.1. Comparison of Aforementioned Formability Tests....................................19

Table 3.1. Mechanical properties of the Al 6061-T6 alloy.

Table 4.1. The match between FEM predictions and experimental observations for

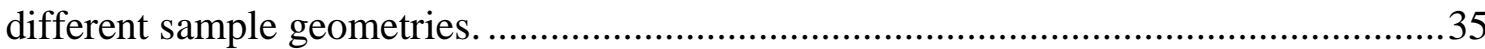




\section{LIST OF FIGURES}

\section{FIGURES}

Figure 2.1. Examples of AHSS and lightweight sheet metal parts in automobile and

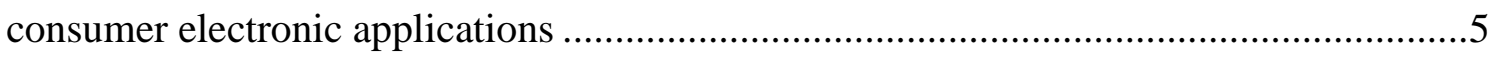

Figure 2.2. Mechanical Behavior of Different Steel Grades............................................6 Figure 2.3. Surface defects that occur during sheet forming. Listed by physical dimensions in ascending order (a-f). Typical grain size is about 50 micrometers ..............8

Figure 2.4. A Schematic Forming Limit Diagram for fracture and for necking. ..............9

Figure 2.5. Schematic Drawing of Hydraulic Bulge Test Tool........................................11

Figure 2.6. Schematic Drawing of Nakazima Test Tool...............................................12

Figure 2.7. Schematic Drawing of Marciniak Test Tool.................................................13

Figure 2.8. Schematic view of the biaxial test. ........................................................15

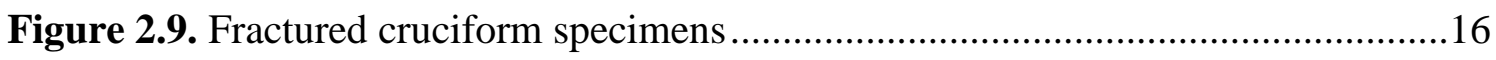

Figure 2.10. A biaxial tensile test with a cruciform sample .............................................17

Figure 2.11. The proposed cruciform specimen designs ..............................................17

Figure 3.1. The portable biaxial test apparatus. .......................................................22

Figure 3.2. a. Microstructure of the rolling directional surface of the center. …….........23

Figure 3.3. Representative true stress-strain curve of Aluminum 6061-T6 alloy. ..........24

Figure 3.4. Dimensional details of 5 cruciform designs..............................................25

Figure 3.5. Schematic drawing of the test setup showing the multiaxial sheet forming and imaging assembly. A 2D DIC method is given as an example for obtaining strain distributions on the sheet surface

Figure 3.6. Integration of high-speed, high-resolution optical camera and objective in the

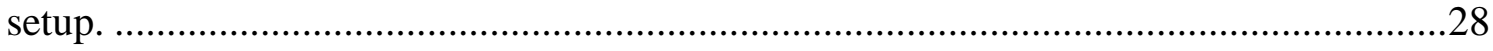

Figure 3.7. Hand drilling machine. .29

Figure 4.1. Linear FEM simulations of the Equivalent Von Mises Stress (Mpa) distributions in cruciform samples 1 (b) and 2 (a). Inset shows the geometry of the pit. 31 
Figure 4.2. Linear FEM simulations of the Equivalent Von Mises Stress (Mpa)

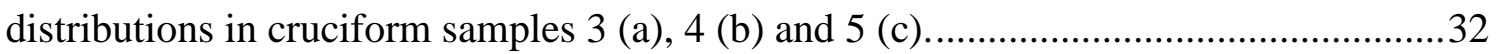

Figure 4.3. The FEA result and the test result of the sample with a hole. .....................34

Figure 4.4. Test result of Sample 2 that failed from the edges of the pit base...............34

Figure 4.5. Linear FEM simulations of the Equivalent Von Mises Stress (Mpa) distributions in Sample 1 having two different pit geometries. Maximum stress is collected at the center for both the bowl-shaped pit (a) and tapered pit (b). Insets provide the details of the pit geometries.

Figure 4.6. Depth profile of the tapered pit machined with custom-made end-mills by benchtop drilling machine.

Figure 4.7. Depth profile of the tapered pit machined with custom-made end-mills by $\mathrm{CNC}$ machine. Inset shows the surface roughness of the pit base with $\mathrm{Ra}=4.23 \mu \mathrm{m}$...38

Figure 4.8. Strain maps showing the principal Green-Lagrangian strain distribution in the pit base just before fracture of Sample 1. $E_{x x}=E_{1}$ (left) and $E_{y y}=E_{2}$ (right). Two diagonal strain bands are visible in the maps. Also, subset size is indicated as black circle.

Figure 4.9. Strain map of shear Green-Lagrangian strain $\left(E_{x y}\right)$ of Sample 1 in the pit base marking the center region of the pit (1 mm diameter) where equibiaxial conditions are satisfied.

Figure 4.10. $\mathrm{E}_{\mathrm{xx}}$ Green-Lagrangian strain results of biaxial test of Sample 1. .41

Figure 4.11. SEM images from the fractured sample showing the necking (a) and cupand-cone type fracture (b) at the corners. (c) SEM image at the $1500 \mathrm{X}$ magnification. Ductile fracture is evident in the neck whereas edges show shear-type fracture.

Figure 4.12. Schematic drawing of the sample (a) and SEM images (b) showing the location of the strain bands. Surface protrusions are visible in the strain bands and at the center confirming the plastic deformation of these regions.

Figure 4.13. Strain map of the principal Green-Lagrangian strain $\left(E_{y y}=E_{1}\right)$ in uniaxial tensile testing of the sheet before fracture. The sharp, tilted local neck common in uniaxial tensile testing is visible in the map. .45

Figure 4.14. Microstructure scale strain map. .46 
Figure 4.15. Comparison of the limiting effective strains under equibiaxial condition as a function of $\mathrm{n}$ for various multi-axial tests and materials. The constant ratio lines, $\varepsilon / n=$ $4, \varepsilon / n=3, \varepsilon / n=2$, classify the materials and tests. Our results for Al 6061-T6 $(\varepsilon / n \sim 3)$ surpass the limiting strains for similar materials tested by cruciform and other

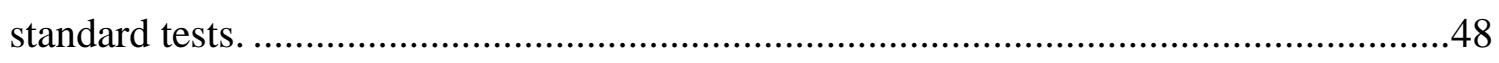




\section{LIST OF SYMBOLS}

\section{SYMBOLS}

$\begin{array}{ll}\mathrm{E}_{\mathrm{xx}}=\mathrm{E}_{1} & : \text { The principal Green-Lagrangian strain in the rolling direction } \\ \mathrm{E}_{\mathrm{yy}}=\mathrm{E}_{2} & : \text { The principal Green-Lagrangian strain in the transverse direction } \\ \mathrm{E}_{\mathrm{xy}}=\mathrm{E}_{3} & : \text { The principal Green-Lagrangian strain in the thickness direction } \\ & \quad \text { (Shear Green-Lagrangian strain) } \\ \varepsilon_{\mathrm{xx}}=\varepsilon_{1} & : \text { The median true principal strain in the rolling direction } \\ \varepsilon_{\mathrm{yy}}=\varepsilon_{2} & : \text { The median true principal strain in the transverse direction } \\ \varepsilon_{\mathrm{xy}}=\varepsilon_{3} & : \text { Equivalent strain (the limiting effective strain) } \\ \bar{\varepsilon} & : \text { Strain hardening exponent }\end{array}$


xviii 


\section{CHAPTER 1}

\section{INTRODUCTION}

The mechanical behavior of materials can be tested under different loading conditions such as uniaxial tension, equibiaxial tension, plane strain, pure shear, etc. [1]. While uniaxial tension is most common testing method in metals, multiaxial deformation tests such as hydraulic bulge, semi-spherical punch (Nakazima), flat punch (Marciniak) and in-plane biaxial (cruciform) are capable of accessing the complex stress states that can realistically simulate the metal forming and deformation processes [2],[3]. Except the cruciform, these tests can also achieve large equivalent (effective) strains compared to the uniaxial tension, which allows the observation of strain hardening and fracture behavior of metals under large strains typical to industrial forming and deformation methods. Achieving large strains and controlling strain paths in the multi-axial tests should be useful for small-scale (microstructure scale) testing of materials which have deformation mechanisms sensitive to their unique microstructural features [4-9]. Studies focusing on local deformation behavior of lightweight metals like aluminum and magnesium alloys and multi-phase materials like dual phase steels have shown that micro-mechanisms of deformation alters the macro-scale behavior [10]. These microstructure scale studies focusing on local deformation mechanisms of these materials have linked the have complex forming behavior compared to regular steels. 
The large scale (about $1 / 4-1 / 3$ meter) and complexity of the standard multi-axial tests, however, have restricted their application to small-scale and in-situ testing. Smaller samples (few $\mathrm{cm}$ ), in-plane deformation are usually necessary for micromechanical analysis [11]. Hydraulic bulge is an out-of-plane, large-scale testing method. Additionally, Nakazima test achieves biaxial stresses by utilizing different sample geometries, but the common drawbacks are out-of-plane deformation, large samples and friction between the samples and the punch. Marciniak is another in-plane stretching test, capable of large strains. Frictionless punch designs are available and different sample geometries allow various stress states. Although Marciniak test is an in-plane stretching test, full-field measurement with the assembly of high-speed, high-resolution optical camera and objective is a challenge.

Apart from the standard methods, cruciform test stands out as another candidate for small-scale, frictionless, in-plane testing. For a successful cruciform specimen, the region of uniform biaxial stress should be maximized and the shear stresses in the test region should be minimized. In addition, a stress concentration outside of the test section should be avoided [12]. Otherwise, the specimen may fail outside of the test region leaving the test region undeformed. As a result, one need to size the specimen to obtain yielding in the test section, i.e. center of the specimen, before failure elsewhere in the specimen.

Even for the most recent experiments having successful center fracture, the measured strain values are relatively small compared to the forming limits of the tested materials. In the work of Liu et al. (2015), Aluminum AA5086 alloy reached the equivalent strain of 0.3 just before the failure [9]. Banerjee et al. (2015) have studied both hot-rolled low carbon steel and cold-rolled AISI 1008 steel. The largest equivalent strains were 0.27 and 0.38 , respectively [13]. Deng et al. could obtain principal strains $\left(\varepsilon_{1}, \varepsilon_{2}\right)$ of 0.04 for DP590 steel [14]. Aluminum 6016 sheet 
reached the equivalent strain of 0.11 in a study by Merklein and Biasutti [15]. Mitukiewicz et. al. (2016) have proposed an unorthodox design and have measured the maximum equivalent strain as 0.08 for cold-rolled DC 5 steel sheet [16]. In another recent study, the equivalent strain was 0.22 during biaxial deformation of low carbon ferritic steel sheet (DX 54) [17].

In this study, we demonstrate a biaxial testing apparatus for in-situ testing of smallscale samples. We also identify the essential design features and manufacturing steps of the sample for obtaining large strains and fracture at the center. Our setup consists of a custom-made microscope and a high-resolution digital camera for microstructure scale imaging and two-dimensional digital image correlation (2DDIC) software for strain analysis. The strain analysis and test results by comparing them with uniaxial and other standard tests such as Nakazima, Marciniak and hydraulic bulge are validated. 


\section{CHAPTER 2}

\section{LITERATURE REVIEW}

\subsection{Formability Behavior of Lightweight Alloys and Advanced High Strength Steels}

Sheet metals has a wide range of application in automotive, aviation and also mobile electronics industry (Figure 2.1) [18, 19]. Weight savings, fuel efficiency, low material and production costs are significant issues. The use of AHSS and lightweight sheet metals are increasing to address these issues. AHSS and lightweight sheet metals are more susceptible to defect formation during forming (pressing, stamping, deep drawing, piercing, etc.) operations compared to conventional steels [20]. Additionally, more complex parts can be produced with a high geometrical accuracy thanks to better formability of conventional steels [20].
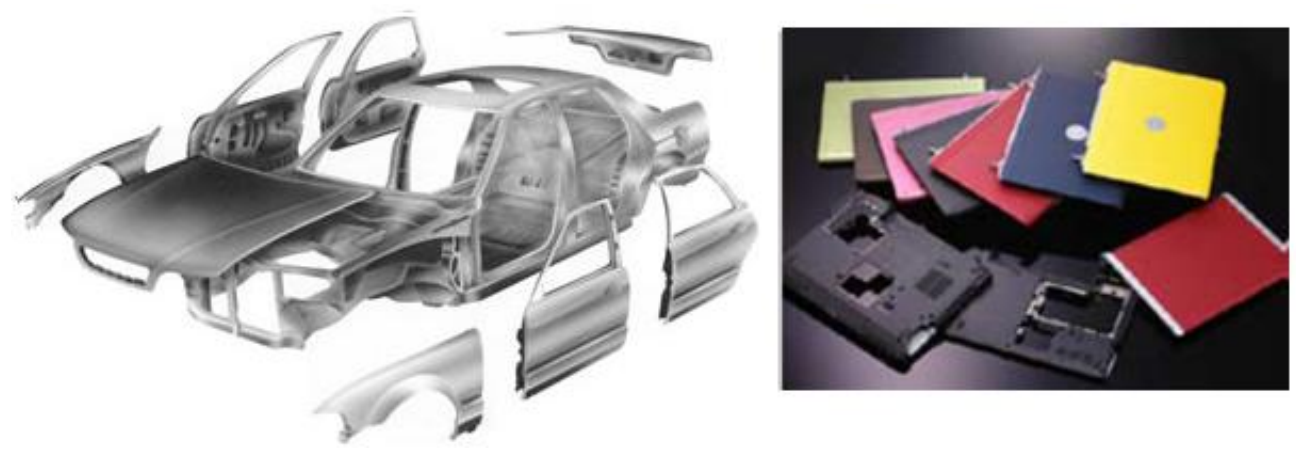

Figure 2.1. Examples of AHSS and lightweight sheet metal parts in automobile and consumer electronic applications [18, 19]. 
Forming of steels become increasingly difficult as they become stronger. AHSS, which are much stronger than conventional steels, are capable of high formability thanks to high work-hardening rate [21]. The main difference between the conventional steels and AHSS is the microstructure.

When yield strength values exceed $550 \mathrm{MPa}$, steels are named as AHSS (Figure 2.2) [21]. The AHSS family has been classified with the 'generation' term. The first generation of AHSS, which includes Dual Phase (DP) steels, TransformationInduced Plasticity (TRIP) steels, Complex-Phase (CP) steels and Martensitic (MS or MART) steels, have a primarily ferrite-based microstructure [22]. On the other hand, Twinning-Induced Plasticity (TWIP) steels, shear band strengthened (SIP) steels and Al-added lightweight steels with induced plasticity (L-IP) have been categorized as second generation of AHSS. There are high manganese contents in these austenitic steels [22].

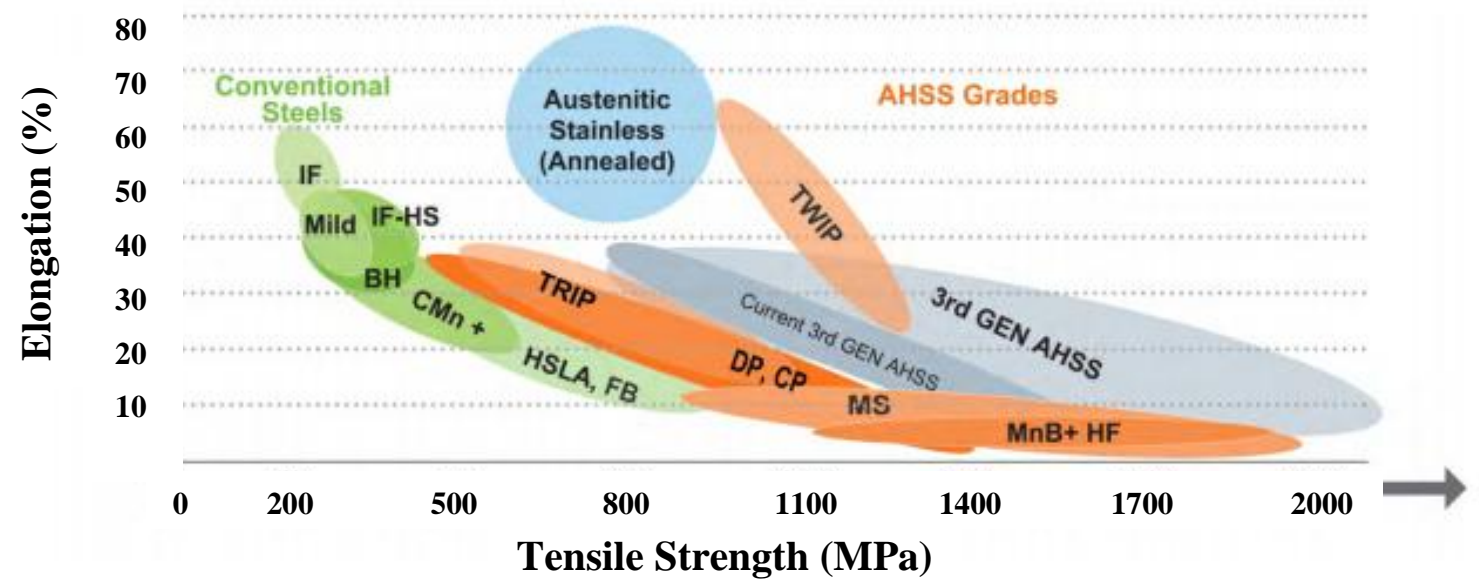

Figure 2.2. Mechanical Behavior of Different Steel Grades [21].

There has been a research about third generation of AHSS in recent years. The developments are improved strength-ductility combinations compare to the first generation of AHSS and lower cost compared to the second generation of AHSS [22]. According to the recent modelling works, the third generation of AHSS will 
include materials with complex microstructures consisting of a high strength phase such as ultra-fine grained ferrite, martensite, or bainite phase with substantial ductility and work hardening [22]. Broad application of lightweight magnesium alloy sheet is restricted by its low workability and formability, both in the production of sheet by conventional rolling and in the forming of sheet into components. The limited number of slip systems, intrinsic to the hexagonal closed pack crystal structure, restricts the formability. Furthermore, rolling results in a strong basal texture with the c-axis aligned nearly parallel to the sheet normal direction, which geometrically restricts basal slip in subsequent sheet forming. Therefore, sheet forming is normally conducted at high temperatures where secondary slip systems are activated [10]. On the other hand, 6061, which was used in this study, is a precipitation hardened aluminum alloy. It contains magnesium and silicon as its major alloying elements [10].

With the increasing use of the light alloy and AHSS parts made of sheet, defects that arise during the sheet forming processes and their relationships with the microstructure have become an important problem [23]. Microstructure-related surface defects that may particularly arise during the forming and shaping operations are shown in Figure 2.3. With their dimensions in ascending order, these defects can be listed as; (a) dislocation glide traces, (b) surface cracks, (c) orange peel effect, (d) individual surface deformation by soft and hard phases, (e) ridging and roping phenomena and (f) the shear bands [24].

Figure 2.3 shows that most of the defects are stemmed from microstructure (individual grains). They may appear on the surface of the material, and can be difficult to eliminate or restore [25]. The formation of these defects are better understood and suppressed in steel plates. It is one of the reasons that steels are still widely used despite their weight disadvantage. 
(a)

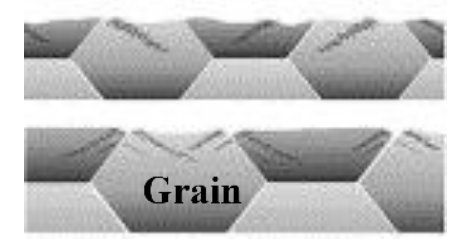

(b)

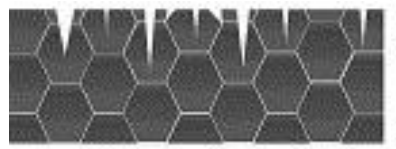

(c)

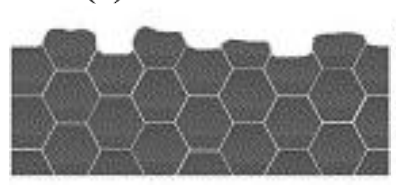

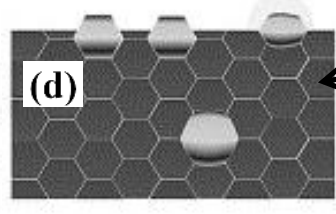

(e)

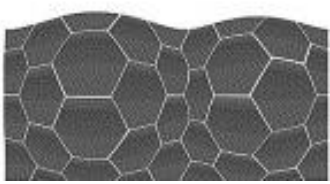

(f)

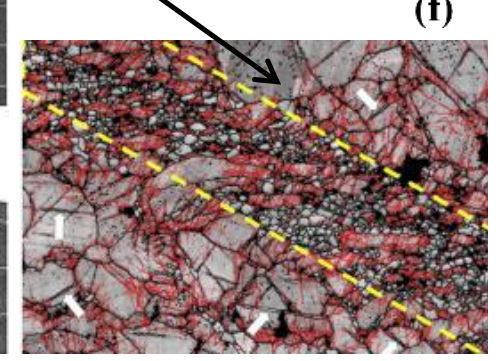

Figure 2.3. Surface defects that occur during sheet forming. Listed by physical dimensions in ascending order (a-f). Typical grain size is about 50 micrometers [25].

The deformation and fracture mechanisms at grain scale can be observed, achieving strain maps by microstructure scale. Accordingly, microstructure forming tests should be used to determine material behavior at grain scale.

\subsection{Introduction to Formability Testing of Sheet Metals}

Formability or ductility of materials can be tested at various loading conditions such as: uniaxial tension, biaxial tension, plane strain, pure shear, etc (Figure 2.4). In addition to establishing the limiting strains at the biaxial tension state, strain hardening behavior of the material can be plotted over a wider strain range [26]. Alternatively forming limit curve (FLC) can be plotted by simulating, one can combine the strain hardening curve with yield functions [26] and construct forming limit diagrams (FLD) using theoretical models such as: Swift [27], Hill [28] or Marciniak-Kuckzynski [29]. 


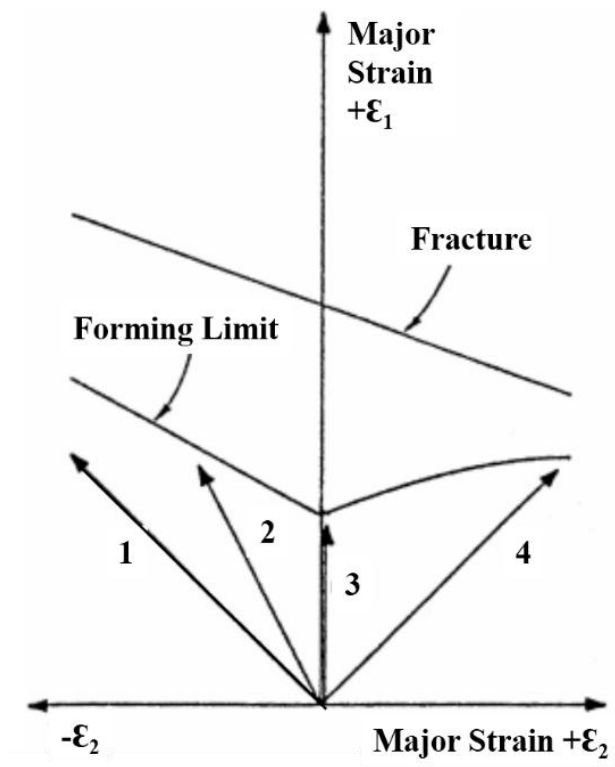

Figure 2.4. A Schematic Forming Limit Diagram for fracture and for necking. 1-Pure Shear $\left(\varepsilon_{1=}-\varepsilon_{2}\right), 2$-Uniaxial Tension $\left(\varepsilon_{1=}-2 \varepsilon_{2}\right)$, 3-Plane Strain $\left(\varepsilon_{2}=0\right)$, 4-Biaxial Tension $\left(\varepsilon_{1=} \varepsilon_{2}\right)[26]$.

For experimental FLD, however, limiting strains at the plane strain, pure shear or any other state other than equibiaxial tension are needed. At each stress state, sample geometry needs to be changed. In Figure 2.4, a FLD can better be observed.

While uniaxial tension is most common, there are also tests that can achieve the biaxial stress state. Different forming operation in Figure 2.4 can be achieved by changing the sample geometry. Additionally, forming processes are mostly related to the right-hand side of the FLD. There are two types of tests, which are in-plane and out-of plane test methods, that can reach these loading states. In the biaxial stress state forces are working in two directions, the third direction is the out-of plane direction. Out-of plane tests cause a bending effect on the thickness of the sample. Out-of plane tests such as hydraulic bulge, Nakazima [26] and in-plane 
tests such as Marciniak, cruciform, can access larger uniform strains compared to the uniaxial tension.

\subsubsection{Out-of Plane Tests}

\subsubsection{The Hydraulic Bulge Test}

As for the specific types of tests, the hydraulic bulge test has a setup which includes an upper and a lower die for clamping the specimen. There is also a pressure chamber with a viscous medium. The sample sheet is placed between the dies, as shown in Figure 2.5 [30]. Hydraulic pressure can be build up by a fluid or a gas which is applied from the chamber of lower die to the specimen surface. As long as the ram moves down, the piston pushes the fluid or gas into the chamber, and pressure is generated. In addition, counter pressure can be controlled, changing the diameter of the outlet nozzle. In hydraulic bulge test, sheet metal is stretched instead of being drawn-in because that pressure affects one side of the sample [31]. 


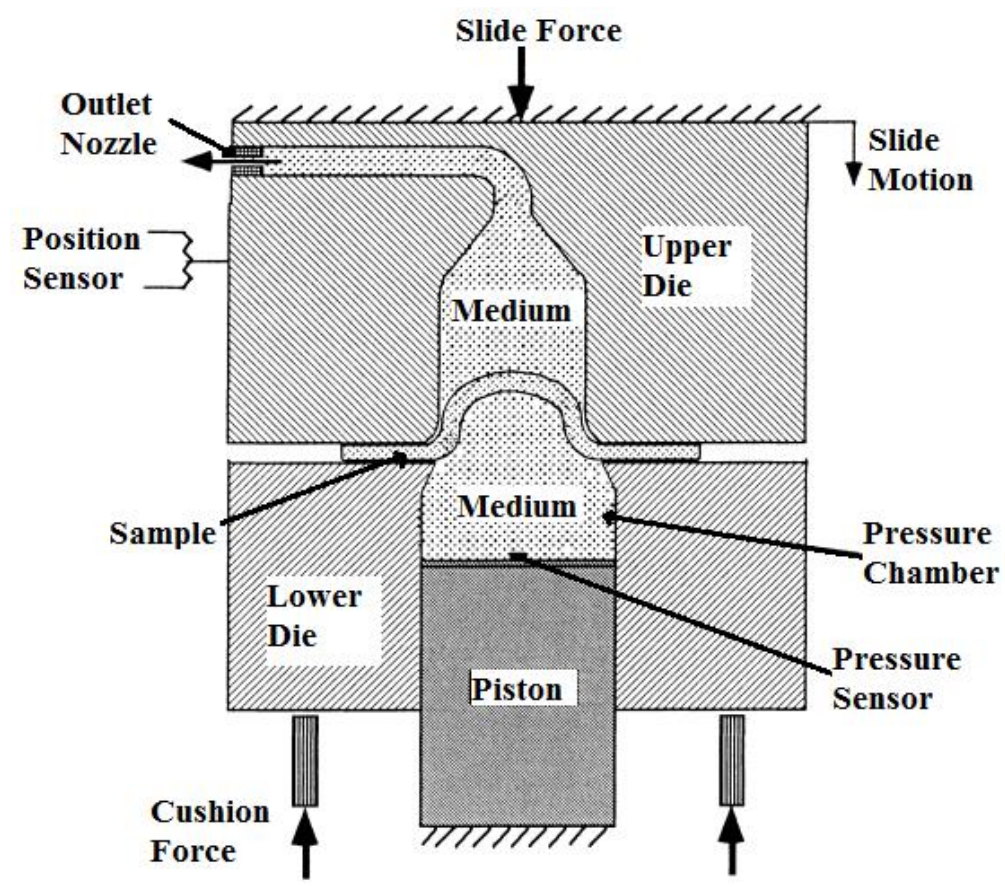

Figure 2.5. Schematic Drawing of Hydraulic Bulge Test Tool [30].

In this method, there are no friction problems due to absence of contact with the test section. Additionally, hydraulic bulge test has no limitations related to tooling or the specimen geometry [30]. While only equibiaxial tension is possible with a circular die, quasi-proportional biaxial tension is possible with an elliptical die [32]. On the other hand, it is hard to monitor the deformation caused by the large height difference between the undeformed and deformed sheets. For this reason, out-of plane tests are complicated for in-situ measurement [33]. As for the other drawback, control of the neck and the crack propagation is a problem because of the high pressure in the test setup [30]. 


\subsubsection{Nakazima Test}

In Nakazima Test, sheet metal specimens having varying widths are deformed by using a hemispherical punch and a circular die [34]. This technique has a simple tooling and specimen geometry, as shown in Figure 2.6 [35]. According to the ISO 12004 standard, punch diameter is shorter than $25 \%$ of the specimen length [26]. Additionally, the formability of sheet metal sample increases when the radius of the punch decreases [26]. Although the punch test works in strain path with $\varepsilon_{1}>0$, $\varepsilon_{2}$ can be both negative and positive [26]. Unfortunately, strain path cannot be changed during the test.

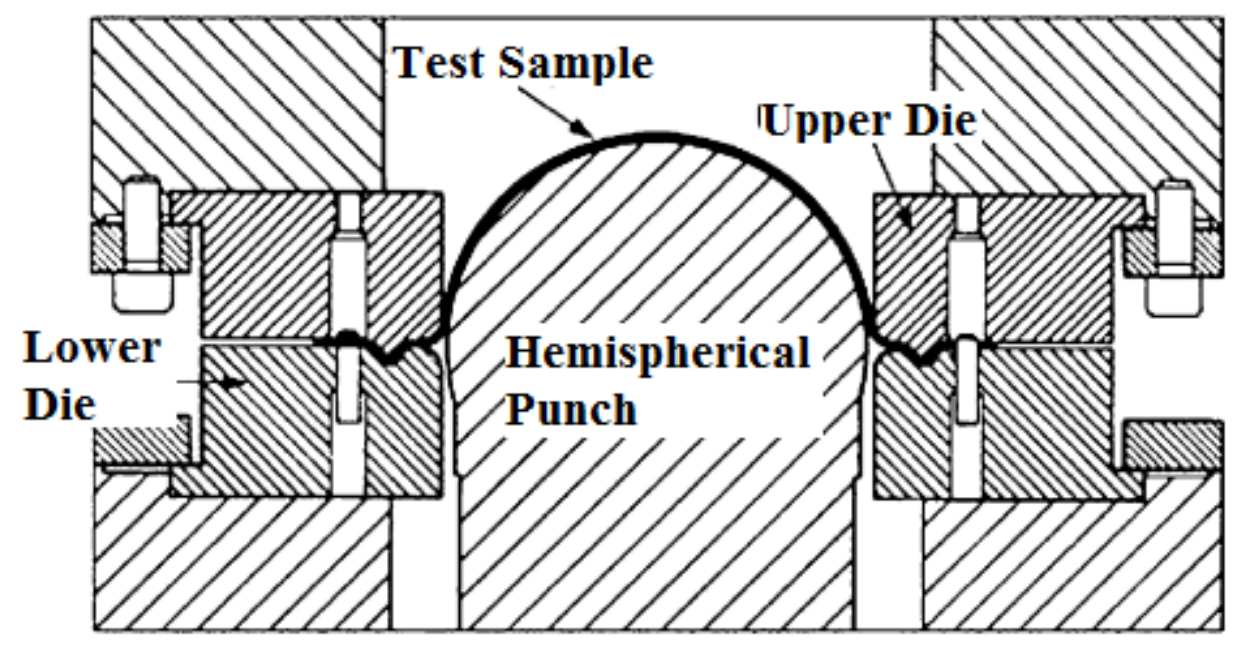

Figure 2.6. Schematic Drawing of Nakazima Test Tool [35].

However, as for the limitations about the Nakazima test friction and bending effects are significant [33]. This method requires use of convenient lubricant to observe uniform stress and strain distribution. Lastly, it is an important problem for out-of plane tests which is a constraint to perform full field measurement [33]. 


\subsubsection{In-plane Tests}

\subsubsection{Marciniak Test}

A third type of test, the Marciniak test also helps to achieve biaxial stress states. Figure 2.7 shows the schematic drawing of Marciniak test tooling [36]. A flat punch having a washer helps to concentrate deformation in the test area. There happens no friction effect on the center of the sample because of hole in the washer. As a result, the largest strain and true in-plane deformation can be obtained in the central section of the sample because of the hole [37].

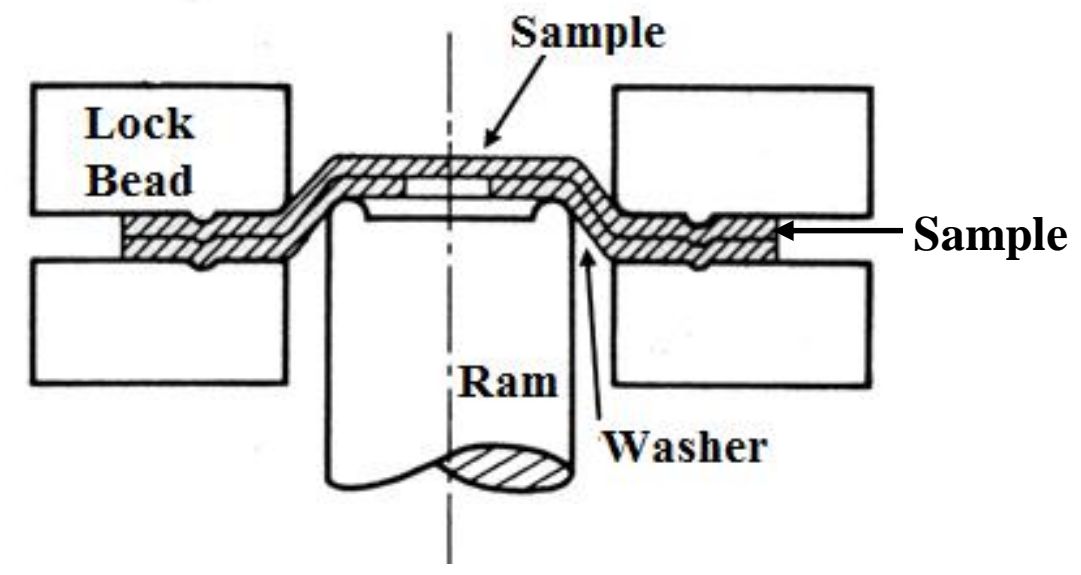

Figure 2.7. Schematic Drawing of Marciniak Test Tool [36].

If the washer and the sample geometries are modified, forming limits in different strain states between uniaxial and balanced-biaxial tensions can be achieved [38]. Although the punch test works in strain path with $\varepsilon_{1}>0, \varepsilon_{2}$ can be both negative and positive. Stress field can be computed provided that the center of the specimen remains steady during the test [26]. However, 2D DIC analysis does not exist in literature although an $\mathrm{x}$-ray system can measure the full 3D stress tensor of the sheet in si-tu under multiaxial tension [36]. On the other hand, a miniature setup is 
demonstrated for microstructure scale testing of sheets within a scanning electron microscope (SEM) [39]. While SEM can provide high resolution images necessary for deformation analysis at the microstructure scale, high speed and high temperature tests remain to be a challenge $[11,39,40]$.

\subsubsection{Cruciform Test}

As an alternative to out-of plane tests biaxial testing utilizing cruciform specimens have been developed since the sixties. At first, Shiratori and Ikegami (1967) designed an in-plane configuration that had a loading system with four servo hydraulic actuators. However, the center of the specimen could not stay stationary during the test in this device [15]. In 1973, Hayhurst attached two spools to each loading axis in order to solve the shifting issue. This machine could stay steady under loads for long times. For this reason, biaxial creep tests started to be used [15]. In 1992, Makinde et al. have improved another design which consisted of a loading system and a control system [2]. There were two hydraulic actuators on each axis in this device. The specimen could not move because of that the actuators link on the rigid frame. Also a load cell on each arm provided to measure the force. An optimum specimen was produced for this apparatus. However, it was only used for estimating the degree of homogeneity of strain in the test sample so that only researchers obtained low strains with that optimum specimen design [2]. A further biaxial tensile test device was designed by Boehler et al. in 1994. The apparatus manufactured on the vertical frame by contrast with the previous designs. As for the other differences, biaxial force was produced by actuating four screw driven pistons (independent actuators) with two motors. The specimen remained stable, and the strain ratio could be adjusted in this setup. The strain was measured with strain gauges. In addition, the vertical arrangement of the apparatus could generate a bending effect on the specimen. Moreover, anisotropic materials could distort via rigid clamps in the testing setup [2]. Kuwabara et al. (1998) have linked a 
pantograph mechanism to the setup designed by Shiratori and Ikegami. This mechanism made the displacement of opposite hydraulic actuators equal [41].

As for the test type, we utilized cruciform test (Figure 2.8) that has some advantages over other conventional tests. Essentially all stress states can be achieved in our test, by changing the load ratio across the arms of the cruciform sample [2]. Therefore, formability of materials, especially metals, can be studied over large strains and at various stress states. What is unique about the cruciform shape is that it enables localization of the stresses at the center of the sample without any friction effects [2].

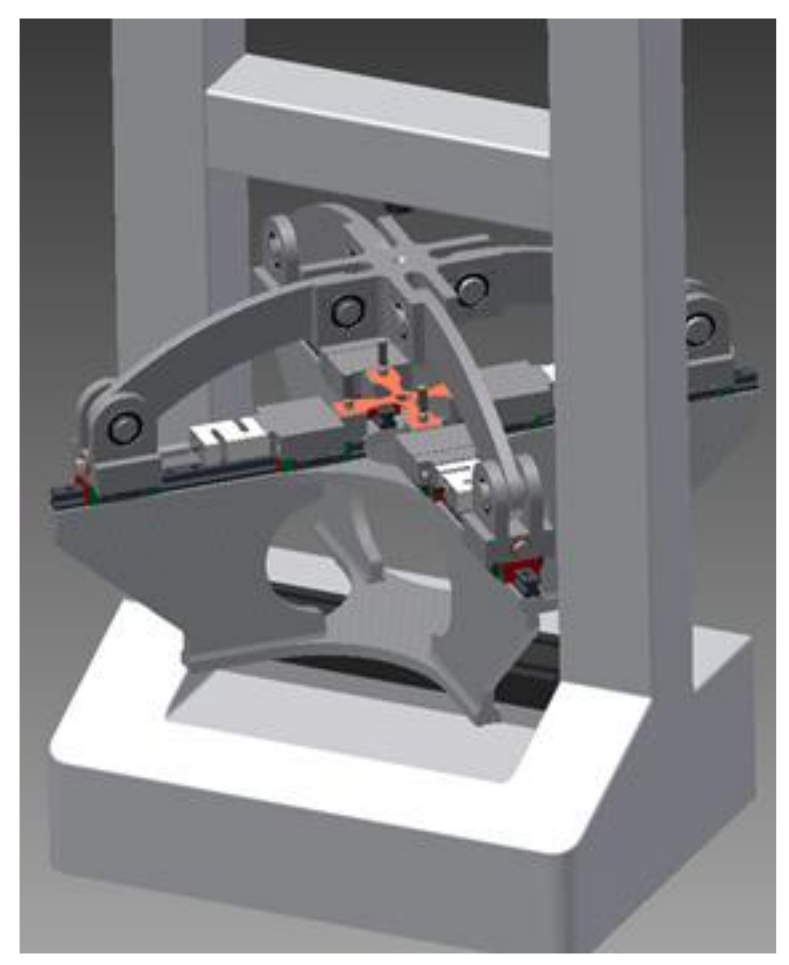

Figure 2.8. Schematic view of the biaxial test. 
During the biaxial cruciform test, sample does not move in the third dimension, and the stresses and strains occur on a plane [2]. This enables the mapping of strains by 2D Digital image correlation (DIC) techniques. Conventional forming tests, on the other hand, require stereo imaging and 3D image correlation techniques, which can be complicated and cumbersome [42]. Moreover, 2D DIC is easily applicable at the micro scale [43] when it is relevant to study the strain distribution at the microstructure scale. Then, microstructural parameters and strain localizations can be correlated and FLDs can be improved for materials like $\mathrm{Mg}$ and $\mathrm{Al}$ alloys [44], where models challenge to incorporate material related parameters.

In literature, there are various designs reported, yet stress localization at the center remains to be an issue. The sample may deform at the arms or corners (intersection of the arms) (Figure 2.9) [45], which may invalidate the test results.
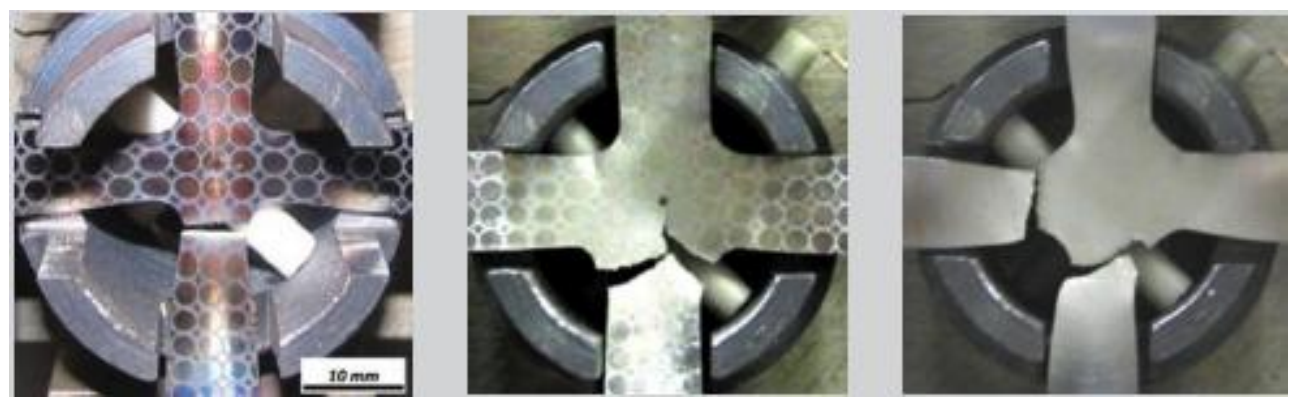

Figure 2.9. Fractured cruciform specimens [44].

Green et al. (2004) have detailed and optimized the dimensions of specimen (Figure 2.10) [46] which was designed by Makinde et. al. in 1992. This large specimen, which has seven slots in each arm, had the most popular design. 


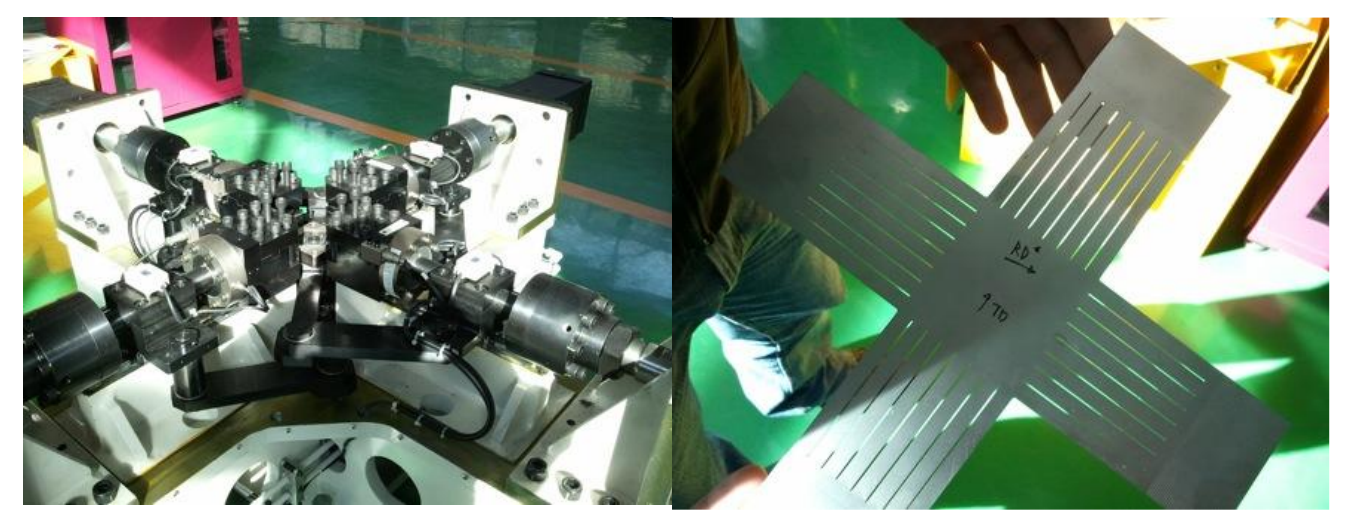

Figure 2.10. A biaxial tensile test with a cruciform sample [45].

For a viable design, large strains with a homogenous distribution should be obtained at the specimen center, followed by the fracture at the same region (Figure 2.11) [47]. The proposed designs in the literature achieve this by incorporating a rounding radius between adjacent loading arms and result in the approximately $\sim 20 \%$ a decrease regarding the thickness of the center $[37,47]$. Slits that are added to arms and a further reduction in the center thickness help collecting the stresses at the center [47]. These features lead to mostly complex and large sample designs requiring stand-alone and dedicated machinery, similar to the standard tests. Nevertheless, fracture may still occur at the slits, arms or fillets in some experiments $[2,39]$.

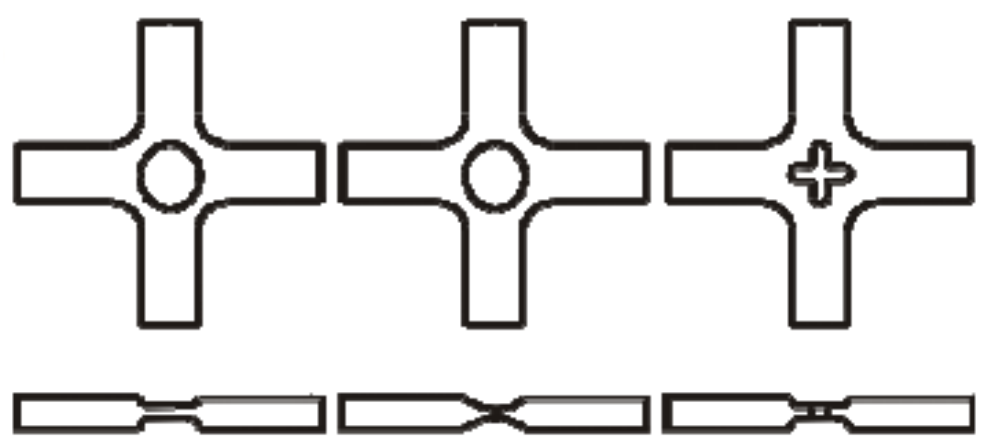

Figure 2.11. The proposed cruciform specimen designs [46]. 


\title{
2.2.3. Comparison of Formability Tests at the Microstructure Scale
}

\begin{abstract}
Although uniaxial tensile testing is more popular, the deformation capacity of sheet metals under multiaxial tension is much more than under uniaxial tension [33]. Multiaxial deformation analyses are capable of large strain. Various multiaxial deformation methods are introduced in Section 2.2, and compared in Table 2.1. It is necessary to consider the mechanical properties not only under uniaxial stress states but also under multiaxial stress states. However, in some cases (Nakazima Test) pure biaxial strain paths (at the center) cannot be observed because of the friction problem [26]. Additionally, in hydraulic bulge test, necking observation become a challenge because of high pressure [26]. Also, importance of small-scale examinations is increasing in order to observation of unique microstructure features. Unfortunately, when the miniature test setup is designed for hydraulic bulge test and Nakazima test, pressure and friction effects increase. As for the other drawback for these type of tests, it is difficult to monitor the deformation. Marciniak test is an in-plane test contrary to hydraulic bulge and Nakazima tests, but the high-speed and high temperature applications are still a challenge due to usage of SEM [36]. At this point, cruciform test is the best option for the small-scale examination and large strain observation.
\end{abstract}


Table 2.1. Comparison of Aforementioned Formability Tests

\begin{tabular}{ccccc} 
& $\begin{array}{c}\text { Hydraulic } \\
\text { Bulge Test }\end{array}$ & $\begin{array}{c}\text { Nakazima } \\
\text { Test }\end{array}$ & $\begin{array}{c}\text { Marciniak } \\
\text { Test }\end{array}$ & $\begin{array}{c}\text { Cruciform } \\
\text { Test }\end{array}$ \\
\hline $\begin{array}{c}\text { Multiaxial } \\
\text { Deformation }\end{array}$ & $\checkmark$ & $\checkmark$ & $\checkmark$ & $\checkmark$ \\
Large Strain & $\checkmark$ & $\checkmark$ & $\checkmark$ & $\checkmark$ \\
$\begin{array}{c}\text { Easy to } \\
\text { Miniaturize }\end{array}$ & X & X & X & $\checkmark$ \\
$\begin{array}{c}\text { Suitability for } \\
\text { 2D analysis }\end{array}$ & X & X & & $\checkmark$ \\
Frictionless & $\checkmark$ & X & $\checkmark$ & $\checkmark$ \\
\hline
\end{tabular}




\section{CHAPTER 3}

\section{EXPERIMENTAL}

\subsection{Biaxial Test Apparatus}

Test mechanism, as shown in Figure 3.1 (upper body of the apparatus), was designed and manufactured in collaboration with UTEST Company (Ankara, Turkey) and it was inspired from [48]. The lower body of the apparatus houses the imaging unit, which is detailed in Section 3.3. The whole apparatus is designed to be portable and can be integrated to any simple uniaxial, bending or compression universal test machine. In this case, it is integrated to a Shimadzu Bending Test Machine with a capacity of $10 \mathrm{kN}$. Each axis of the loading mechanism moves independently on a rail and they are all connected to load cells. When the test begins, a software gives the load on each axis once in a second via a data logger. Horizontal load on each axis can be controlled by adjusting the angle between the horizontal axis and the vertical arms that are connected to the test machine, as

$\mathrm{F}_{\text {on axis }}=\left(\mathrm{F}_{\text {machine }} \times \tan \theta\right) / 4$. In equibiaxial setting, $\theta$ and therefore loads are synchronized with a maximum difference of $100 \mathrm{~N}$. This is achieved by placing the cruciform sample in the apparatus and applying $15-25 \mathrm{~N}$ pre-load to each axis by tightening the screws connecting the horizontal axis and the vertical arms with equal length. This way each arm is connected to the axis at a fixed distance from the sample center, making $\theta$ equal for each axis. 


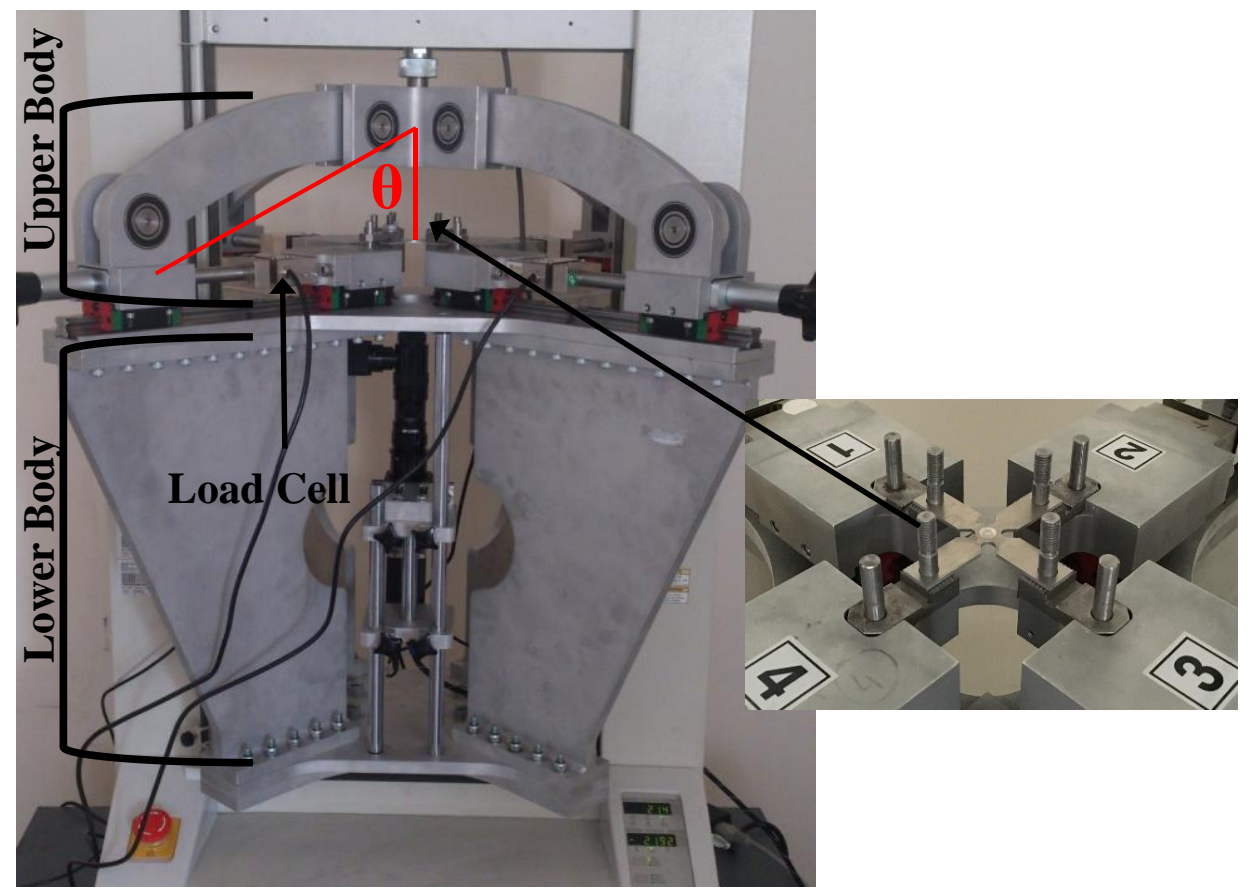

Figure 3.1. The portable biaxial test apparatus.

Currently, only tensile stresses and strains are possible which corresponds to the right-side of the forming limit diagram (FLD). The apparatus can be modified for compressive stresses in order to explore the left side of FLD.

\subsection{Materials \& Methods}

Aluminum 6061-T6 sheet was selected as the sample material due to its uniform microstructure and properties. The $2 \mathrm{~mm}$ thick sheet purchased from Aleris Aluminum; Duffel, Belgium, had a grain size of $58 \pm 15 \mu \mathrm{m}$ (Figure 3.2 (a)) and average hardness of $108 \pm 4 \mathrm{~kg} / \mathrm{mm}^{2}$ (HV). 


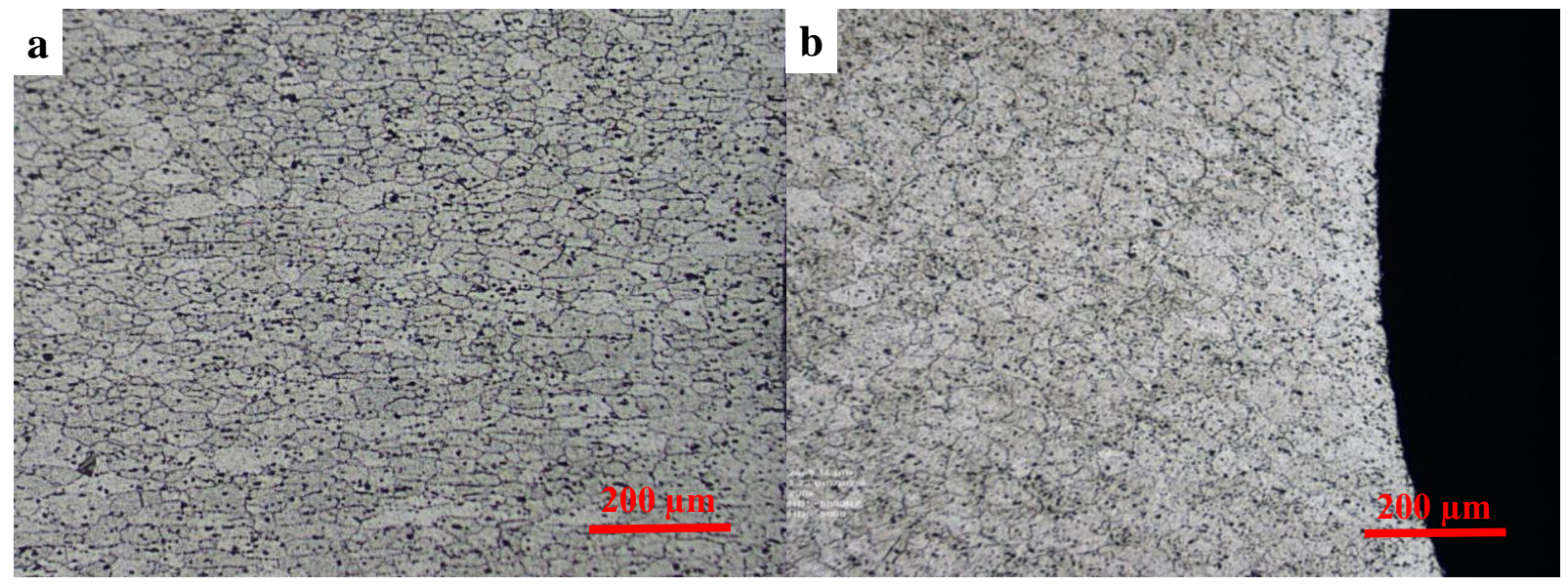

Figure 3.2. a. Microstructure of the rolling directional surface of the center.

b. Microstructure of the rolling directional surface of the laser-cut edge.

Table 3.1 documents the average tensile properties of the sheet.

Table 3.1. Mechanical properties of the Al 6061-T6 alloy.

\begin{tabular}{cc}
\hline $\begin{array}{c}\text { Tensile Stress at Yield (Offset } 0.2 \%)^{\mathbf{a}}(\mathrm{MPa}) \\
\text { Maximum Tensile Stress }{ }^{\mathbf{a}}(\mathrm{MPa})\end{array}$ & $270 \pm 1$ \\
Tensile Strain at Break ${ }^{\mathbf{a}}(\%)$ & $16.5 \pm 1$ \\
Strain Hardening Exponent & $0.115 \pm 0.001$ \\
Microhardness $\left(\mathrm{kg} / \mathrm{mm}^{2}\right)$ & $108 \pm 4$ \\
\hline${ }^{\mathbf{a}}$ Obtained from the engineering stress-strain curve \\
${ }^{\mathbf{b}}$ Calculated from the true stress-strain curve
\end{tabular}

At least seven samples were laser cut parallel to the rolling direction and dimensions were based on ASTM E8. Tensile tests were conducted in an Instron 5582 universal tensile test machine with extension controlled of $3 \mathrm{~mm} / \mathrm{min}$ rate and strain data were measured by a video extensometer. Except the strain hardening 
exponent, all properties were determined from engineering stress-strain curves. Figure 3.3 shows the representative true stress-strain curve used for determining the hardening exponent by means of power law $\left(\sigma=K \varepsilon^{\mathrm{n}}\right)$.

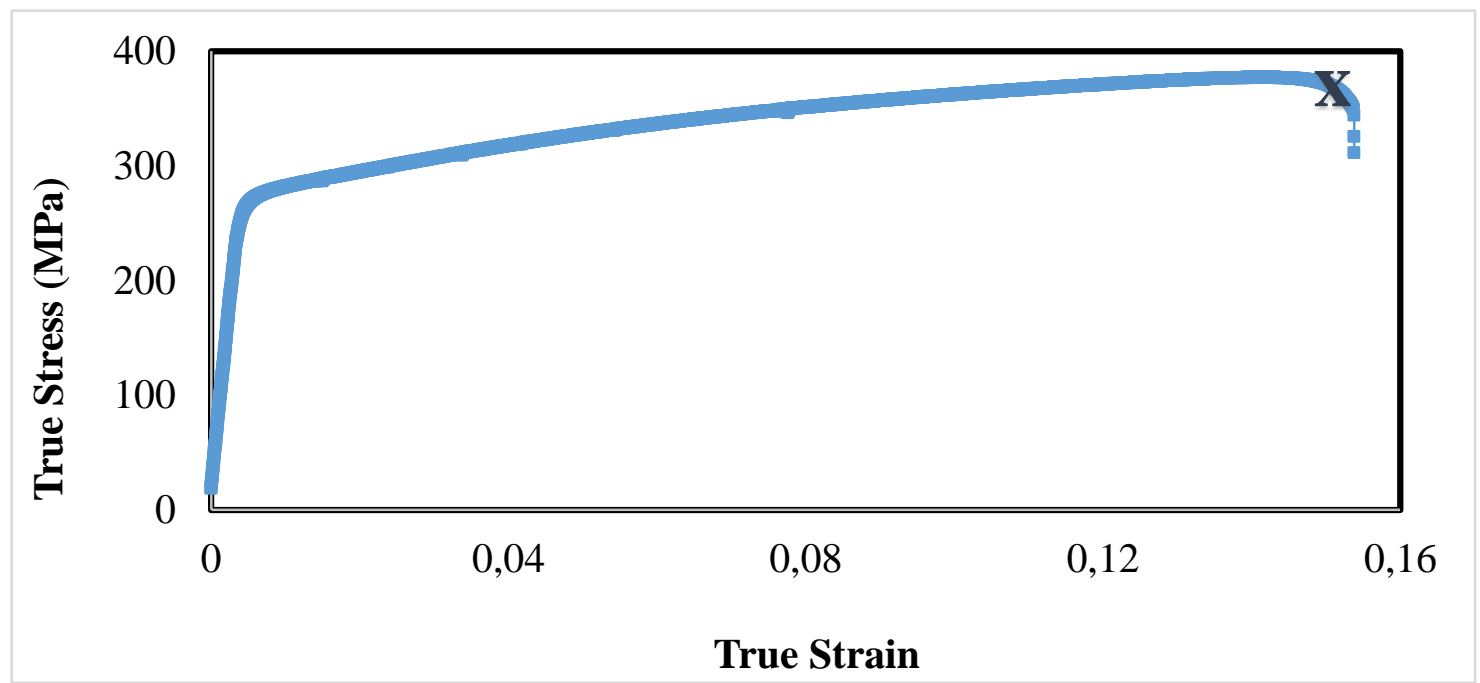

Figure 3.3. Representative true stress-strain curve of Aluminum 6061-T6 alloy.

For biaxial testing, five most common cruciform geometries in the literature [20, 45, 49-52] were investigated and at least 10 laser-cut specimens were tested for each design (Figure 3.4). 

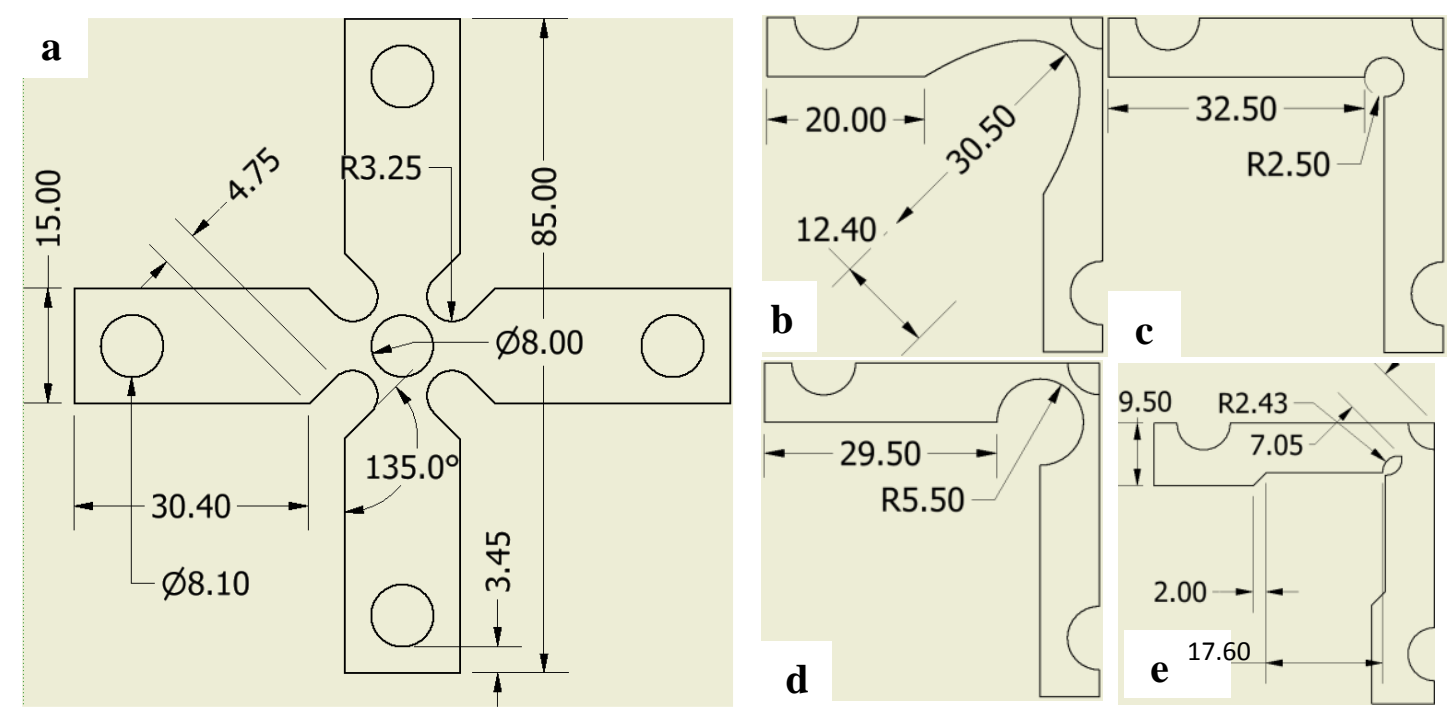

Figure 3.4. Dimensional details ( $\mathrm{mm}$ ) of 5 cruciform designs,

a. Sample 1, b. Sample 2, c. Sample 3, d. Sample 4, e. Sample 5

A detailed microstructural investigation near the laser-cut edges revealed similar grain size $(52 \pm 16 \mu \mathrm{m})$ (Figure $3.2(\mathrm{~b}))$ and micro-hardness $\left(85 \pm 5 \mathrm{~kg} / \mathrm{mm}^{2}\right)$ compared to the sample center. While the edges are somewhat softened, they did not have significant damage in the form of porosities, cracks or resolidified layers. As the test regions of the samples were few millimeters away from the edges and laser cutting did not significantly change the microstructure, it was assumed that the test results were unaffected from laser cutting.

The geometries from the referenced papers were adapted proportionally for smallscale testing with $85 \mathrm{~mm}$ restriction in length and $2 \mathrm{~mm}$ restriction in thickness. The rest of the dimensions were scaled down keeping the same proportions in the original designs (Dimensional details $(\mathrm{mm})$ of 5 cruciform designs). For correct alignment and attachment of the samples to the test apparatus, every design had also laser-cut holes at the $15 \times 15 \mathrm{~mm}$ grip section of each arm. Overall, sample dimensions were $85 \times 85 \times 2 \mathrm{~mm}$ (Dimensional details ( $\mathrm{mm}$ ) of 5 cruciform designs). 
The thickness of the center region was reduced by machining a pit in the sample using a 3-axis CNC milling machine. The pit design and manufacturing steps are detailed in Section 4.2., as they significantly affect the deformation and fracture behavior of the samples. Surface roughness of the machined pits was measured by Mitutoyo Surftest SJ-400. Fractured surfaces were imaged by SEM (FEI Nova 430 NanoSEM) operating at $20 \mathrm{kV}$.

\subsection{Digital Image Correlation Setup}

Strain maps, which give an information about the deformation and fracture mechanisms in material, can be achieved by using a mathematical correlation. While the specimen is in a mechanical test, a series of images are taken with an assembly of high-speed, high-resolution optical camera and objective. DIC requires a computer software in order to calculate the change in pixel intensity (or gray scale value) between two consecutive images by using correlation algorithms. In addition to the applications in mechanics of materials, DIC is widely used in fluid mechanics, biomechanics, and geomechanical areas [53-56]. In solid mechanics applications, specular markers (paint particles) or asperities on a solid surface create the contrast needed to correlate the images. After obtaining displacement vectors for the tracked pixels (or particles), spatial distributions of strain and strain rate can be mapped (Figure 3.5) [57]. 


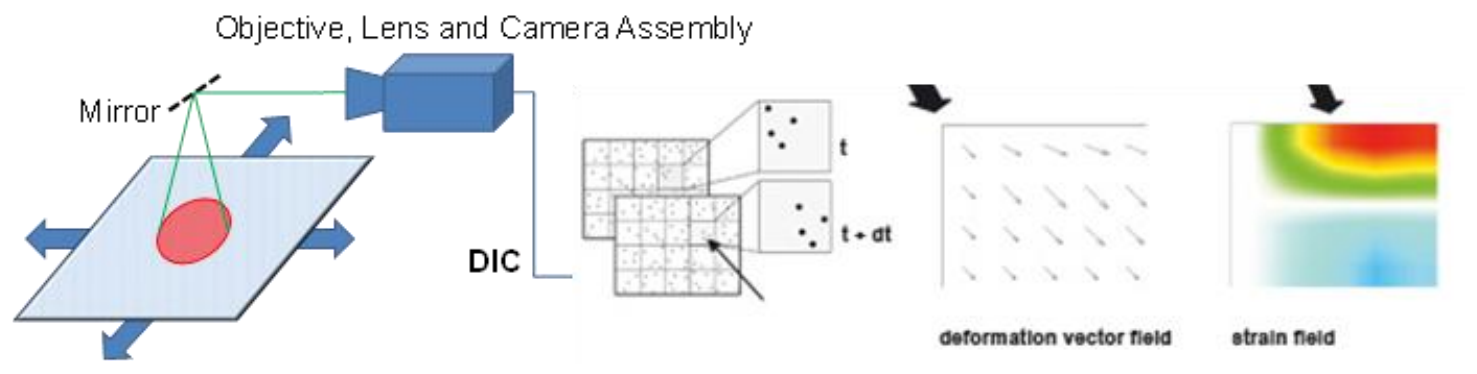

Figure 3.5. Schematic drawing of the test setup showing the multiaxial sheet forming and imaging assembly. A 2D DIC method is given as an example for obtaining strain distributions on the sheet surface [56].

The lower body of the test apparatus (Figure 3.1) is the imaging unit consisting of: a plan-apo objective (Zeiss, 20X, NA $=0.4$, optical resolution $=0.84 \mu \mathrm{m}$ ), a zoom lens assembly (Navitar UltraZoom 6000, 1.40X - 9.00X and NA = 0.023-0.071, respectively) including a coaxial LED illumination and a $2 \mathrm{X}$ adapter, positioning stages and a 5MP digital camera (Basler piA2400-17gm, 2/3" Sony ICX625 CCD sensor) (Figure 3.6). The maximum resolution of the camera is $2448 \times 2050$ pixels at 17 frames per second with a shutter speed of 1/100,000. 


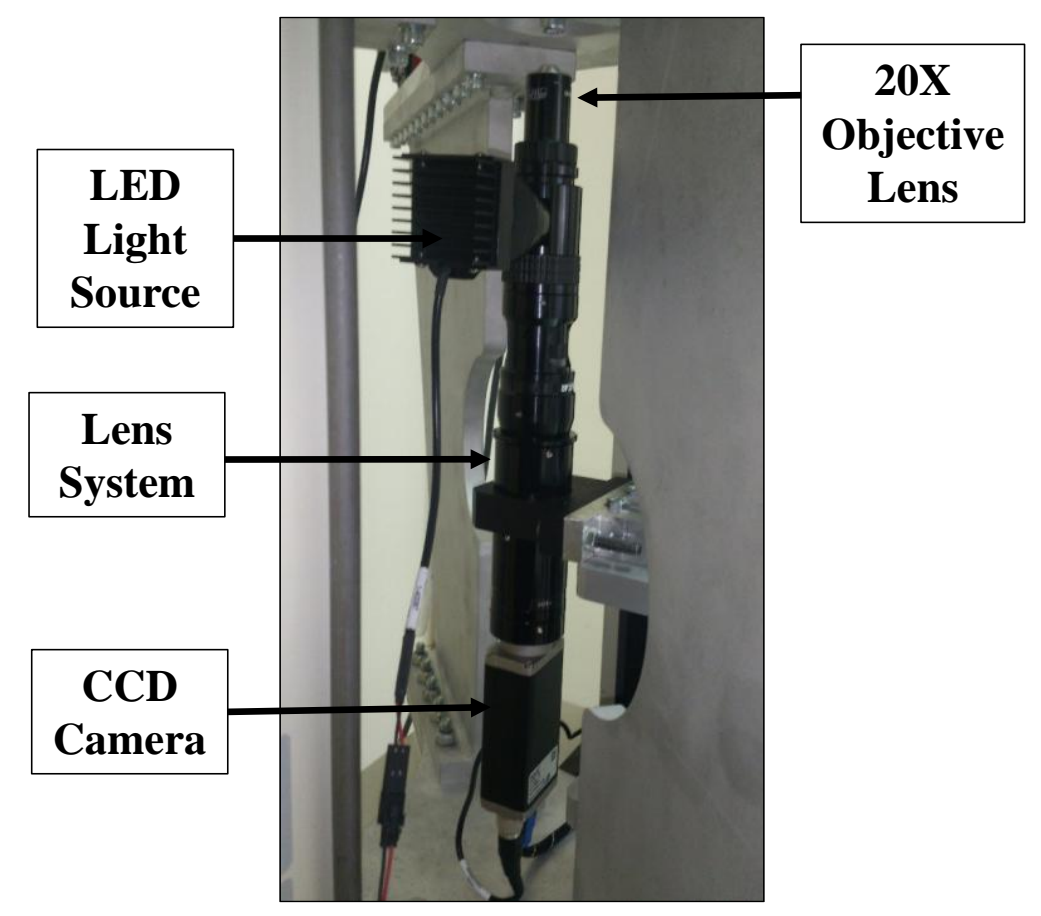

Figure 3.6. Integration of high-speed, high-resolution optical camera and objective in the setup.

Overall magnification range is between 1.40 - 9.00X for macro-scale configuration, and $14-91 \mathrm{X}$ for micro-scale configuration that includes the 20X objective lens. The macro-scale configuration was sufficient for imaging the pit base in biaxial testing ( $2 \mathrm{~mm}$ diameter) as it yields a field of view of $2.9 \times 2.2 \mathrm{~mm}^{2}$ at $3 \mathrm{X}$ magnification. Surface of the cruciform samples were sprayed with a black paint solution to form a random speckle pattern necessary for correlation. Paint solution contained $30 \%$ of acrylic paint and $70 \%$ of acetone and sprayed with an air brush (Bad Sector BD-130 operating at 45 psi pressure) at $10 \mathrm{~cm}$ distance from the sample surface. This process resulted in randomly distributed $\sim 20 \mu \mathrm{m}$ size black dots (speckles). In order to validate the DIC results and to compare biaxial testing with uniaxial, the imaging setup was also mounted onto the tensile test machine. The camera was combined with another lens (Tamron 23FM16L, 16 mm, F/1.4) in 
order to have a larger field of view of $177 \times 147 \mathrm{~mm}^{2}$. This time the black paint was sprayed by a regular paint sprayer, resulting in $\sim 400 \mu \mathrm{m}$ speckles on the surface.

On the other side, the micro-scale configuration had a $0.6 \times 0.5 \mathrm{~mm}^{2}$ field of view at 14X magnification, which allowed imaging of about 200 grains. The natural texture of the sample was used to obtain required speckle pattern. The micro-scale analysis, which did not need to grinding process because of acceptable machining, started with the polishing by using a hand drilling machine (Figure 3.7). $2 \mathrm{~mm}$ diameter zone on the center was polished with diamond paste at a speed of about $250 \mathrm{rpm}$. The diameter of diamond particles are 6,3 and $1 \mu \mathrm{m}$, respectively. Then, the sample was immersed in a solution of $400 \mathrm{ml}$ water, $25 \mathrm{ml} \mathrm{HNO}_{3}, 15 \mathrm{ml} \mathrm{HCl}, 5 \mathrm{ml}$ $\mathrm{HF}$ for $60 \mathrm{~s}$ in order to the microstructural features and etching pits were enough for correlation.

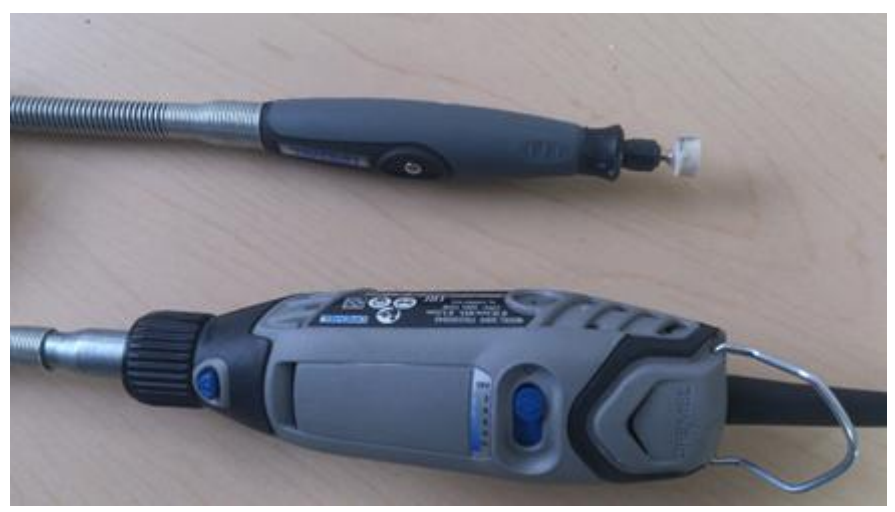

Figure 3.7. Hand drilling machine.

An open source, MATLAB-based program named Ncorr v1.2 was used for the 2DDIC. Details of the correlation algorithms can be found in [58] and on software's website [59]. DIC analysis can be conducted in two methods: cumulative and incremental [60]. The former computes the strain between the first and last image, the latter compares successive image pairs. In large strain analysis, cumulative 
method may not work due to deterioration of the speckle pattern mostly after the plastic deformation. Thus, incremental method was preferred and Ncorr v1.2 has an option for this purpose. When the pattern deterioration was noticed between any two images by naked eye, the images were selected and correlated. Two image pairs were sufficient for the elastic region, whereas in plastic region, 11 image pairs were necessary. Higher number of image pairs (26) changed the total strain value by only 0.01 , yet increased the computing time. Overall, 410 images were captured during biaxial tests, corresponding to $0.5 \mathrm{fps}$ at a deformation rate of $1 \mathrm{~mm} / \mathrm{min}$. For tensile test, the total 410 images corresponded to $1 \mathrm{fps}$ at a deformation rate of $3 \mathrm{~mm} / \mathrm{min}$. The macro-scale DIC analysis of biaxial tests had a subset size (radius) and step size of 80 and 10 pixels, respectively, at a spatial resolution of 0.0012 $\mathrm{mm} /$ pixel. For the images recorded during tensile tests, same parameters were adjusted as 30 and 5 pixels, respectively, at a resolution of $0.07 \mathrm{~mm} /$ pixel. Spatial resolution was $0.255 \mu \mathrm{m} /$ pixel for the microstructure scale DIC, with 40 pixels subset size (radius) and 6 pixels step size, yielding about 2 subsets/grain.

Ncorr calculates the Green-Lagrangian strains $\left(E_{x x}, E_{y y}\right.$ and $\left.E_{x y}\right)$ from the displacement fields [59]. Strain error from the initial rigid body translation tests was found to be $0.14 \%$. Theoretically, rigid body translations should yield no strain. Therefore, strain after the translation must be the error from pattern preparation, optical system (imaging), and correlation algorithm [53]. Ncorr's correlation algorithm error was calculated to be $10^{-13}$ [59]. Similarly, the error from the optical system should be relatively low [53]. Therefore, speckle pattern produces most of the strain error, which was reduced to $0.05 \%$ by optimizing the spraying pressure, distance and solution, which resulted in sharper and smaller speckles. Pattern contrast was also improved by adjusting the lighting conditions. The Green-Lagrangian strains calculated after the tests were converted to true (logarithmic) strains by [61]:

$$
\varepsilon=\ln (\sqrt{2 \mathrm{E}+1})
$$




\section{CHAPTER 4}

\section{RESULTS \& DISCUSSIONS}

\subsection{Sample Design}

Before the tests, five different cruciform designs were simulated with linear FEM using ANSYS R15.0 software (Academic version) in order to obtain stress distributions at a constant load of $3000 \mathrm{~N}$ on each arm (Figure 4.1). Triangle surface mesher was used with $1 \mathrm{~mm}$ of mesh size. It was assumed that the fixing holes are rigidly mounted to the jaws. To simulate this, a frictionless support is applied to the mounting face.

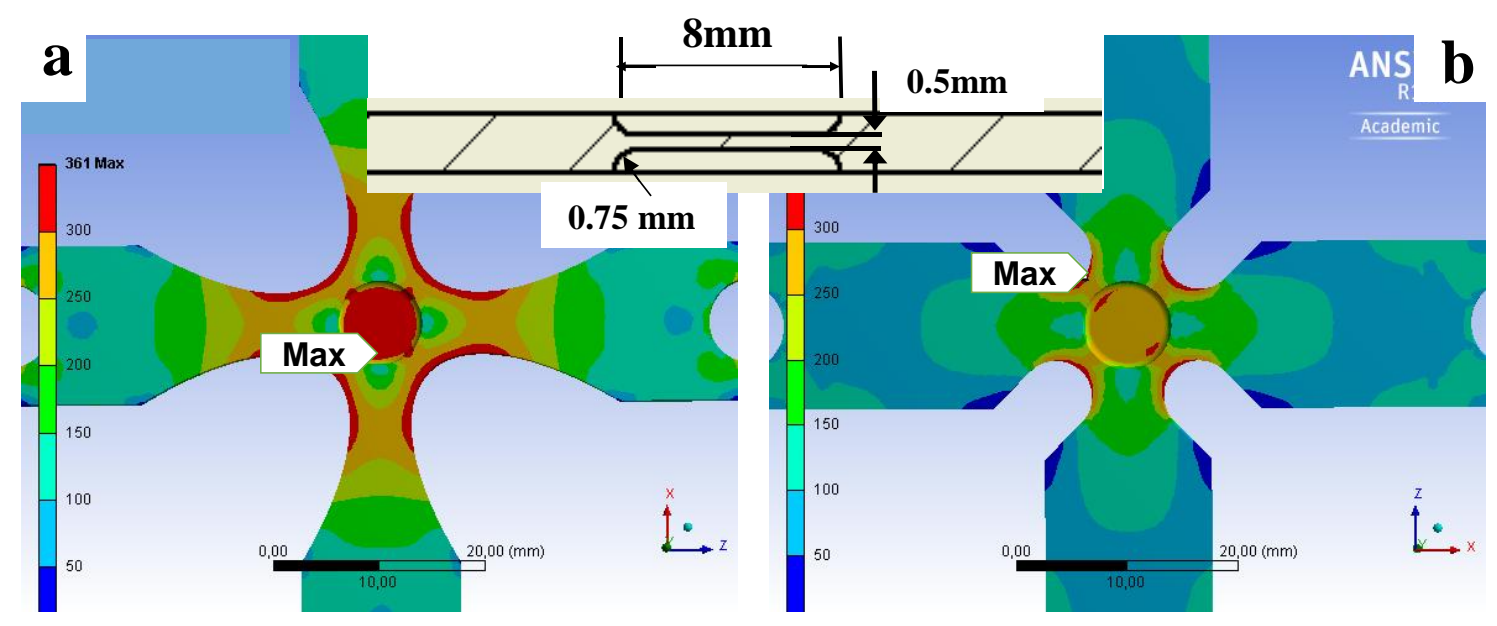

Figure 4.1. Linear FEM simulations of the Equivalent Von Mises Stress (MPa) distributions in cruciform samples 1 (b) and 2 (a). Inset shows the geometry of the pit. 
Samples usually fail from the locations that collected the maximum stress in the elastic simulations, as the plastic deformation should start and accumulate at these locations. Accumulation of plastic deformation is verified by DIC analysis (Section 4.3) and the initiation of fracture is confirmed by videos recorded during the tests. The FEA results of other three designs is shown in Figure 4.2. As it can be seen on the below figure, the rest of designs were not proper to have maximum stress in the center even in the fillet. These three designs were eliminated in the initial experiments because failures were obtained at the arms and also the fixation holes.

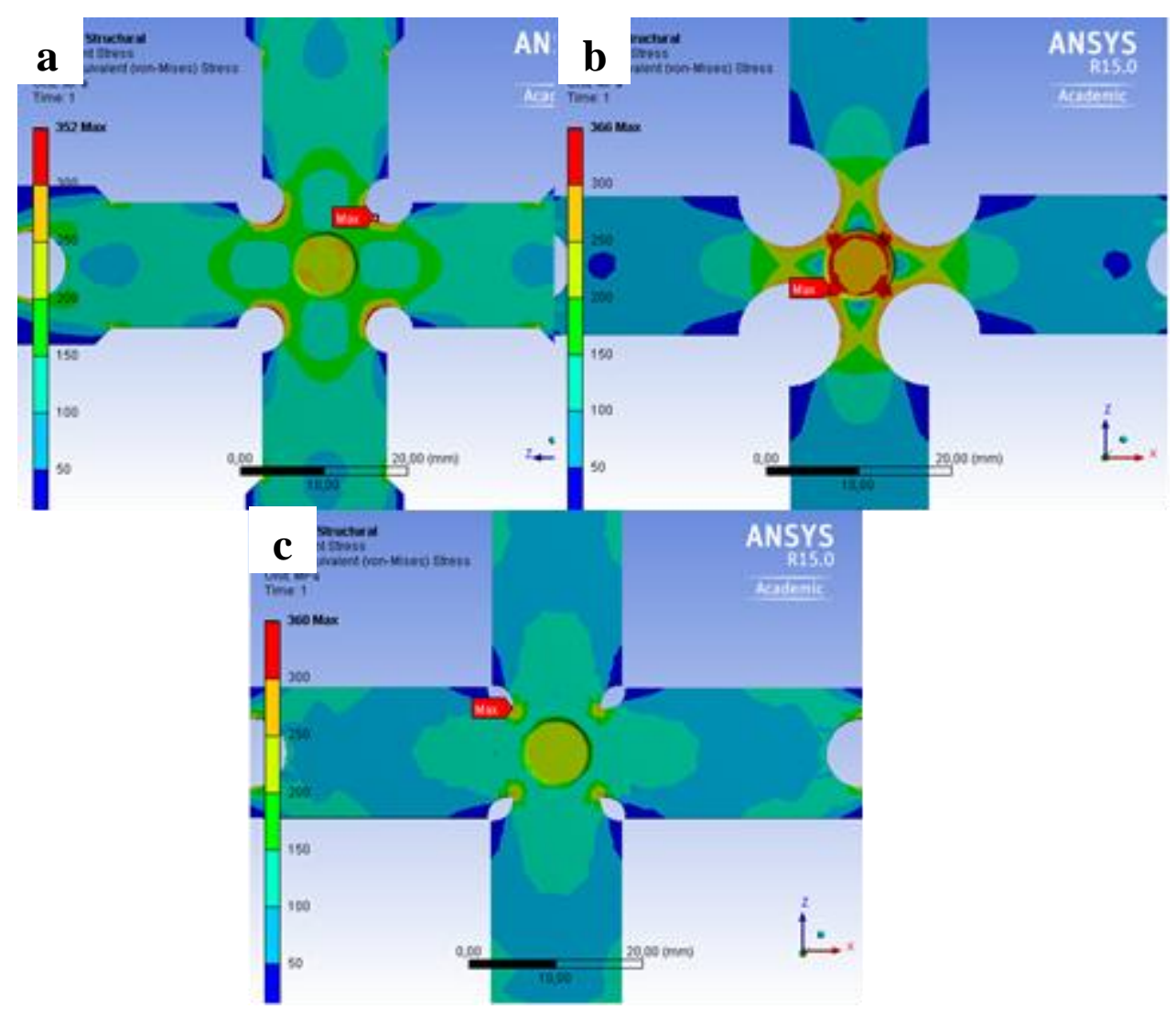

Figure 4.2. Linear FEM simulations of the Equivalent Von Mises Stress (MPa) distributions in cruciform samples 3 (a), 4 (b) and 5 (c). 
On the other hand, the FE analysis for specimen with a hole were done in order to test hole effect on the center fracture. In order to test this experimentally, specimens from sample 1 and 2 have prepared; with reduced cross-section and a hole and only with a hole. Specimens with just a hole have the least percentage of center fracture, around $25 \%$ (Table 4.1). Most of the failure occurred at the arms as FE analysis predicted. The percentage of FE analysis predictions matching the test results is about $75 \%$ (Table 4.1). According to FE analysis results, the stresses around the hole and the arms are close to each other especially for sample 2. The diameter of the hole is varied from $2 \mathrm{~mm}$ to a smaller diameter like $0.1 \mathrm{~mm}$. According to FEA analysis (Figure 4.3) large holes are not successful. The biaxial tension test conditions are not satisfied around the hole. Instead, local uniaxial tension test conditions are observed around the hole. Equibiaxial tension does not occur and shear stresses prevail in the area between the hole and the fillet. However, shear stresses diminish and equibiaxial conditions are achieved as hole diameter gets smaller and approached to $0.1 \mathrm{~mm}$. FEA results of the $0.1 \mathrm{~mm}$ hole strongly resemble the designs without a hole, except the lack of stress concentration at the fillet, corners or arms. Biaxial conditions are satisfied nearly all around the center of the design. The shear stress is nearly zero and the maximum and middle principle stresses are very close to each other. However, drilling a $0.1 \mathrm{~mm}$ diameter hole was a challenge, holes with $0.5-2 \mathrm{~mm}$ diameter were able to drill in the experiments. For the specimens with reduced cross-section and a hole, the percentage of FE analysis predictions matching the experimental observations is about $100 \%$ (Table 4.1). Also all the specimens failed from the center. Necking was again observed at the corners. For this reason, the samples including a hole were eliminated, and it was decided to continue with the sample including only reduced center section. 


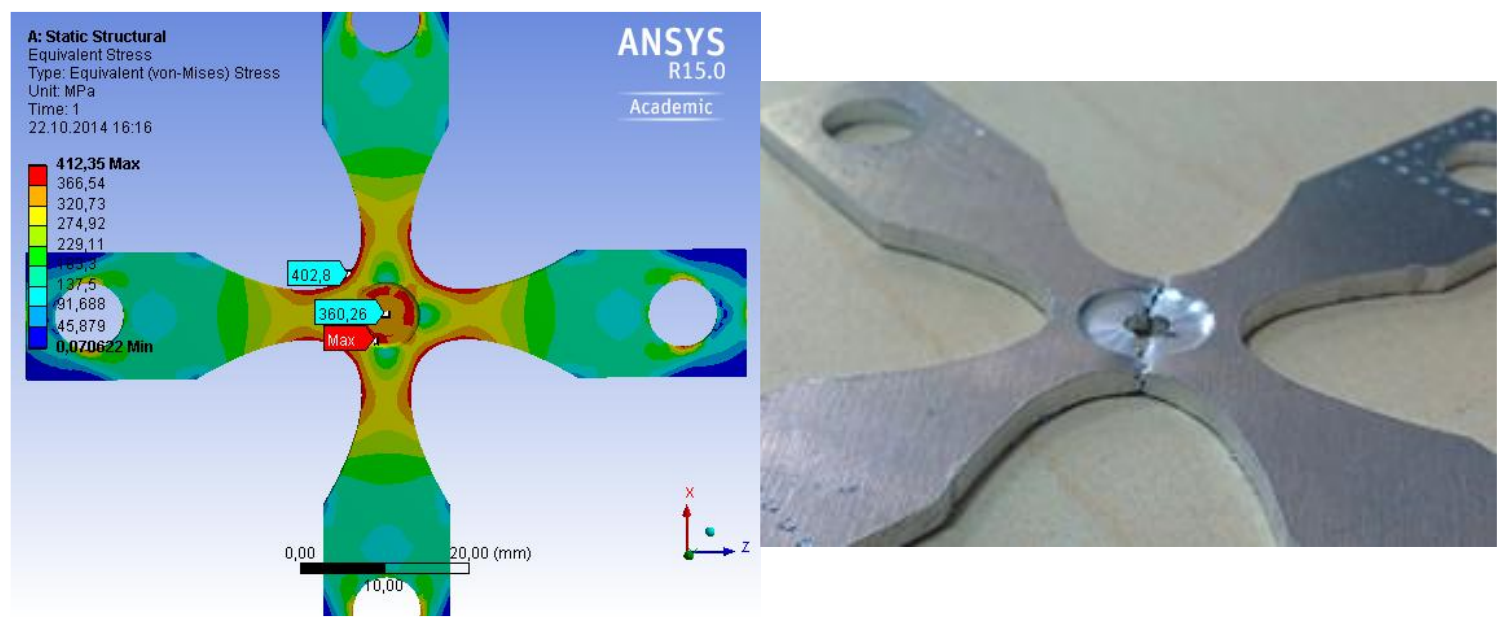

Figure 4.3. The FEA result and the test result of the sample with a hole.

On the other hand, Sample 2 cracks along the fillet (Figure 4.4), where the maximum stress was collected in FEM (Figure 4.1 (a)).

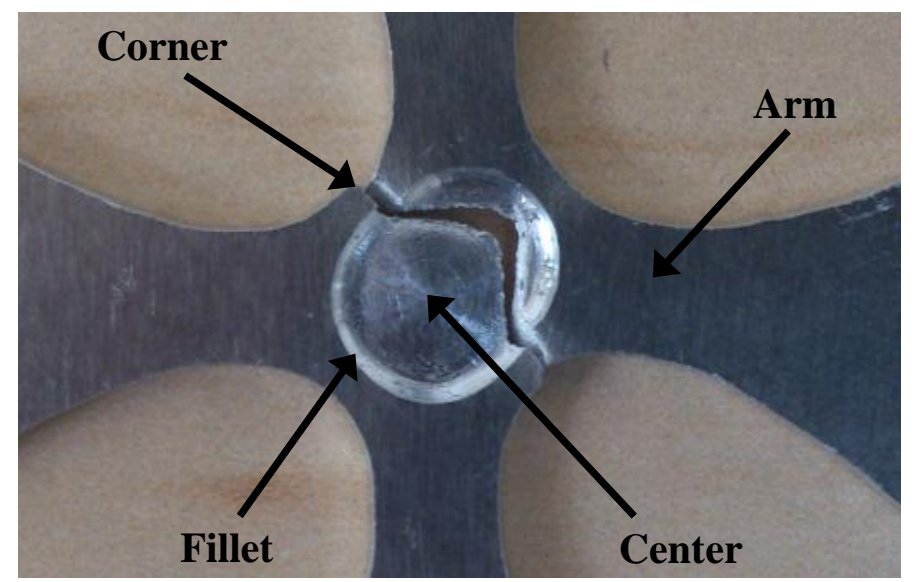

Figure 4.4. Test result of Sample 2 that

failed from the edges of the pit base.

Table 4.1 shows the match and resemblance between FEM predictions and experimental observations for other sample geometries. Samples cracking from the 
maximum stress regions given by FEM are considered as a match. Center deformation or fracture is not observed in any geometry and it was not predicted by FEM. There are no indications of surface protrusions around the center (Figure 4.4) as it is a common indication of plastic deformation in aluminum alloys [1]. Samples prematurely failed from either corners, fillets or arms, which is also a common problem in the literature $[15,45]$. Among all designs, FEM predictions matches the experimental observations in Sample 1 with a success rate of $93 \%$. This sample cracks along fillets and corners, where the stress was concentrated in FEM Figure $4.1 \mathrm{~b}$.

Table 4.1. The match between FEM predictions and experimental observations for different sample geometries.

\begin{tabular}{|c|c|c|}
\hline $\begin{array}{l}\text { Sample Geometry } \\
- \text { [reference }]\end{array}$ & $\begin{array}{l}\text { Test results } \\
\text { matching FEM } \\
\text { predictions }(\%)\end{array}$ & $\begin{array}{c}\text { Possibility of } \\
\text { center fracture }(\%)\end{array}$ \\
\hline $1[66,69]$ & 93 & 0 \\
\hline $2 \quad[65]$ & 50 & 0 \\
\hline $3[65,68]$ & 67 & 0 \\
\hline $4[68,70]$ & 80 & 0 \\
\hline $5 \quad[65,67]$ & 80 & 20 \\
\hline $\begin{array}{l}\text { Design with reduced } \\
\text { cross-section and a hole }\end{array}$ & 100 & 100 \\
\hline Design with a hole & 75 & 25 \\
\hline
\end{tabular}




\subsection{Controlling the Fracture Behavior by Pit Design and Manufacturing}

The success and feasibility of the Sample 1 in initial tests motivated us to modify it by improving the pit designs, which is shown to be another effective way of collecting the stresses at the center [2]. The most important parameter in the pit design is the thickness reduction ratio, which increases the chances of center fracture $[13,40,50]$. A second pit in the original one improves the stress concentration, yet complicates the sample manufacturing [2,9]. We preferred single reduction for simple manufacturing and their maximum reduction was $75 \%$ corresponding to $0.5 \mathrm{~mm}$ thickness. Center region became delicate and fragile below $0.5 \mathrm{~mm}$ thickness. Figure 4.5 compares the two pit designs having different thickness profiles, which is another parameter controlling the fracture behavior [11].

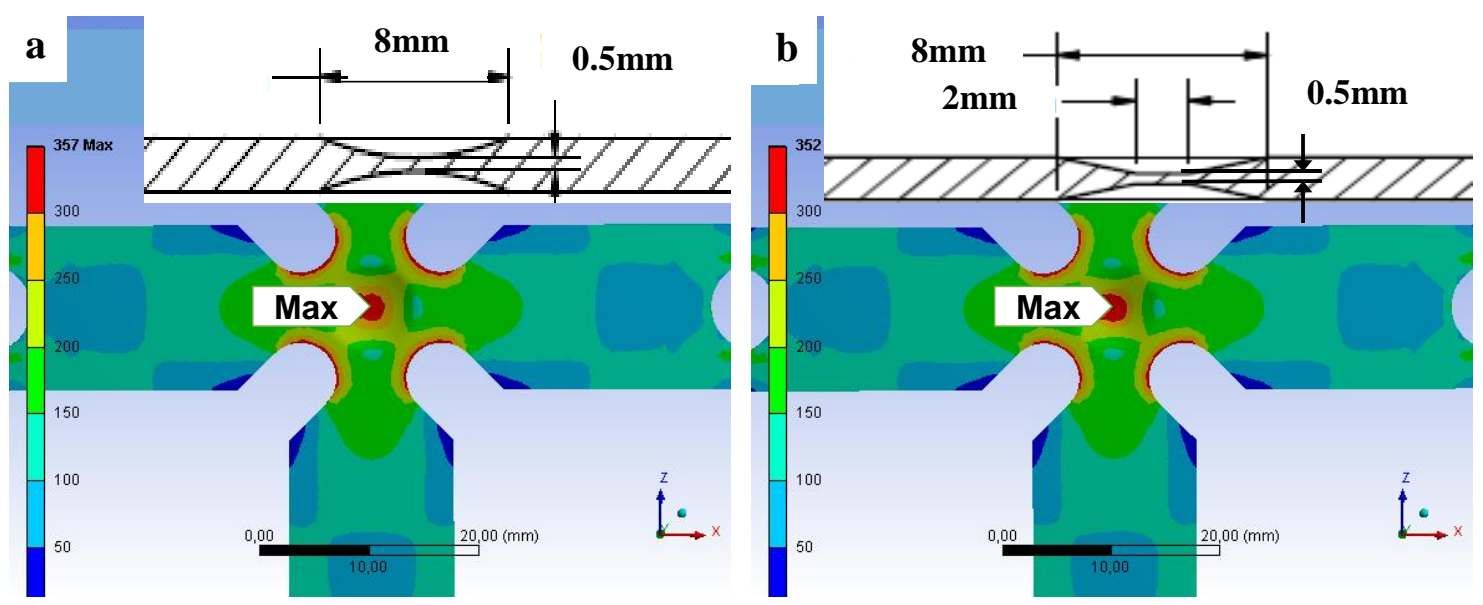

Figure 4.5. Linear FEM simulations of the Equivalent Von Mises Stress (MPa) distributions in Sample 1 having two different pit geometries. Maximum stress is collected at the center for both the bowl-shaped pit (a) and tapered pit (b). Insets provide the details of the pit geometries. 
Filleted profile was eliminated in the previous section as it collected the stresses at the edges of the pit base (Figure 4.1). The bowl-shaped profile in Figure 4.5 (a) is also common in literature [2, 11, 45], easy to machine with a ball end-mill and indeed ensured center fracture during the tests. However, a flat and smooth base is necessary for imaging and 2D-DIC. The imaging setup could not focus on the center region of this design and coaxial light was scattered, resulting in poor images. Moreover, only a small region can be analyzed with this profile and that region may not represent the real material behavior.

The tapered profile in Figure 4.5 (b) was optimized by FEM and machined by two custom-made, end-mills having same taper with the profile but different end diameters. At first, center thickness was reduced by benchtop drilling machine (BOSCH PBD40), and the center fracture cannot be observed. When surface roughness of the pit was measured, as shown in Figure 4.6, a protrusion was determined on the center surface due to low rotational speed of the benchtop tool.

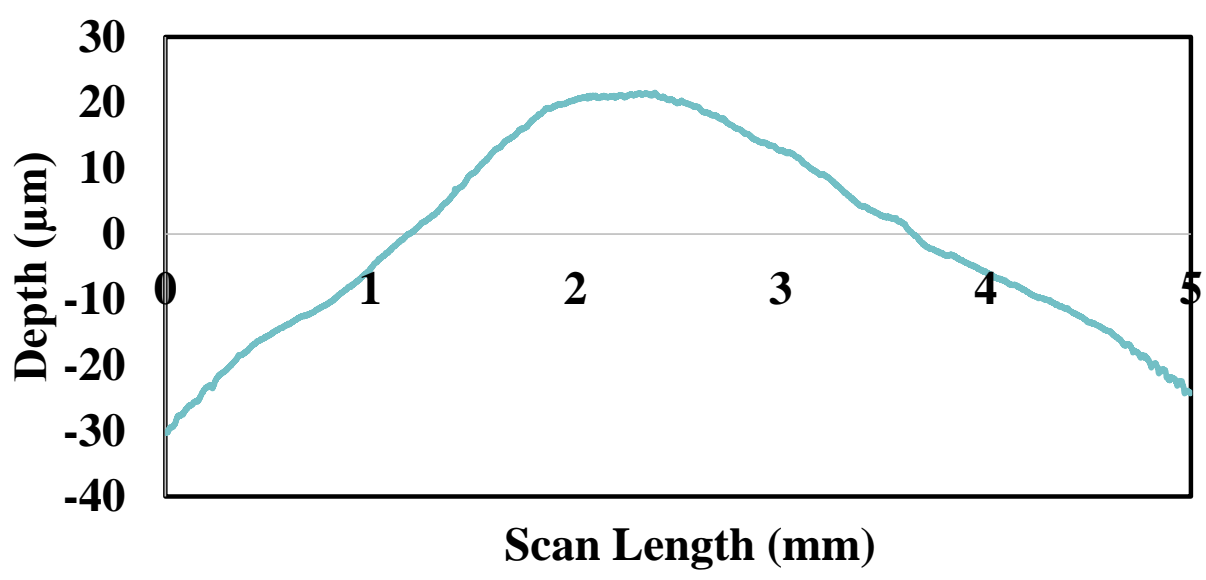

Figure 4.6. Depth profile of the tapered pit machined with custom-made end-mills by benchtop drilling machine. 
Then, CNC milling machine started to be used for manufacturing pit because of higher rotational speed. Two symmetrical pits were machined on each surface of the sample in order to have a constant thickness of $0.5 \mathrm{~mm}$ at the center. First, the end-mill ( $2 \mathrm{~mm}$ end diameter) was used to make pit dimensions exact. The pit was machined in just one step, but the surface finish was not acceptable and some samples failed from the edges of the pit base as the center was slightly thicker ( $40 \mu \mathrm{m})$ than the edges. This is a common problem indicated in the literature [11, $13,15,45]$, and it may arise from the poor machining of the pit. The surface finish, uniform thickness and sharp corners shown in Figure 4.7 were achieved by circulating the smaller diameter $(1 \mathrm{~mm})$ end-mill within the pre-machined pit.

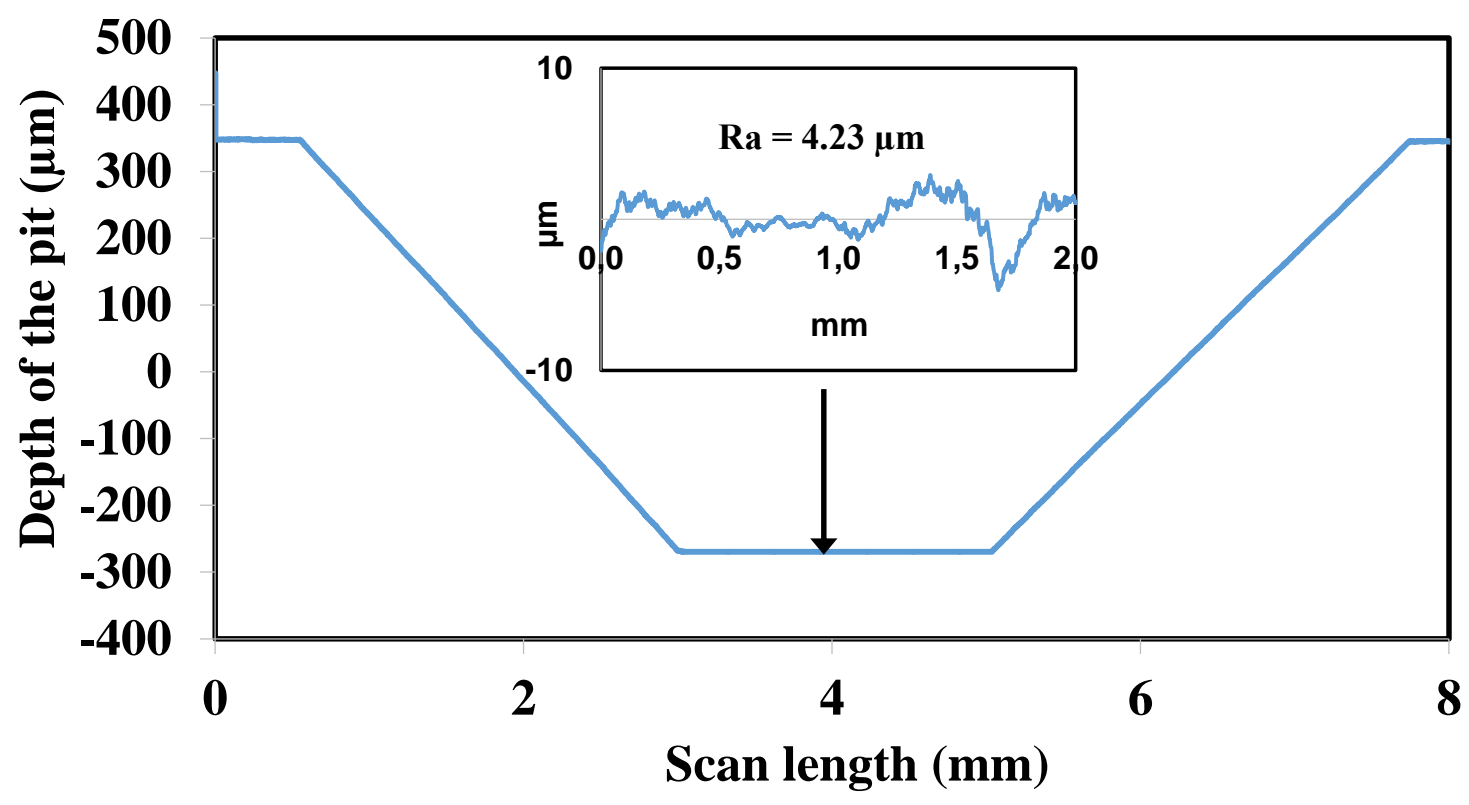

Figure 4.7. Depth profile of the tapered pit machined with custom-made end-mills by CNC machine. Inset shows the surface roughness of the pit base with $\mathrm{Ra}=4.23 \mu \mathrm{m}$. 
Eventually all the samples failed or cracked from the center as predicted by FEM.

Crack initiation and propagation at the center were also recorded during the tests. Besides the pit design, accurate and precise machining was equally important in obtaining center fracture and matching the test results to FEM predictions.

\subsection{Obtaining Large Strains and Fracture at the Center}

Figure 4.8 shows the distribution of the principal strains, $E_{1}=E_{x x}$ and $E_{2}=E_{y y}$, just before the fracture of sample 1 . There were no visible cracks on the surface.
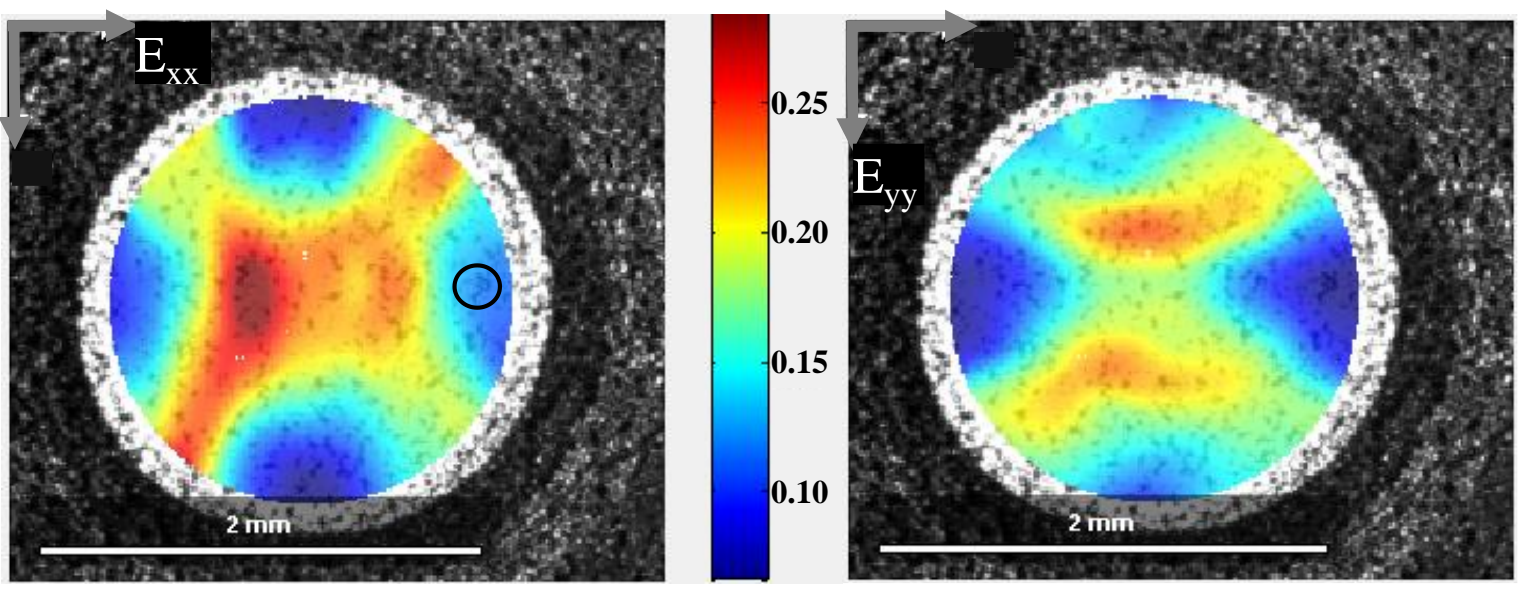

Figure 4.8. Strain maps showing the principal Green-Lagrangian strain distribution in the pit base just before fracture of Sample 1. $E_{x x}=E_{1}$ (left) and $E_{y y}=E_{2}$ (right). Two diagonal strain bands are visible in the maps. Also, subset size is indicated as black circle.

Strains are localized at the center, but for the entire pit base the median true principal strains are $\varepsilon_{1}=0.15$ and $\varepsilon_{2}=0.14$. The true principal strain in the thickness direction is calculated from the constant volume equation: 


$$
\varepsilon_{1}+\varepsilon_{2}+\varepsilon_{3}=0
$$

as $\varepsilon_{3}=-0.29$ and the equivalent strain is given by the following equation;

$$
\bar{\varepsilon}=\sqrt{\frac{2}{3}\left\{\varepsilon_{1}^{2}+\varepsilon_{2}^{2}+\varepsilon_{3}^{2}\right\}}
$$

and calculated as $\bar{\varepsilon}=0.29$. The source of localized strain at the center can be two diagonal bands present in the strain maps (Figure 4.9). These bands connect the diagonal corners of the sample and cross each other at the center. Outside the bands, the strains are lower, $\varepsilon_{1} \approx \varepsilon_{2} \approx 0.11$, and close to the strain hardening exponent (n) of the material.
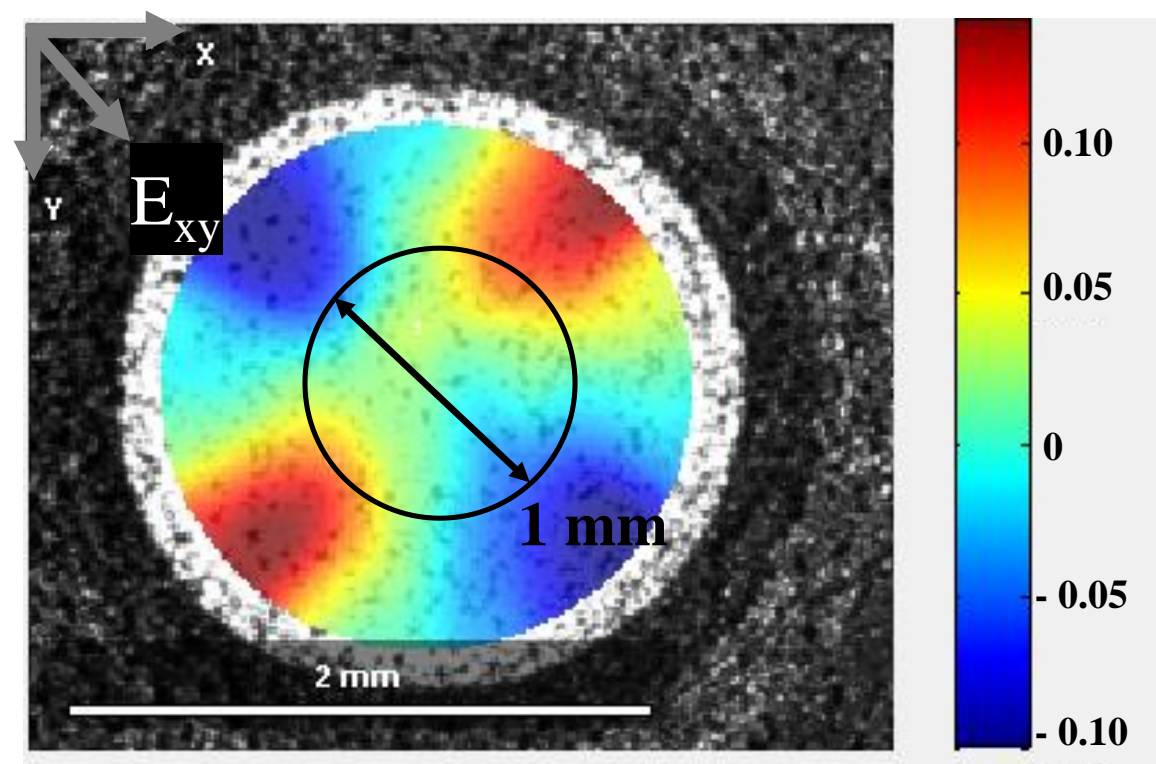

Figure 4.9. Strain map of shear Green-Lagrangian strain $\left(E_{x y}\right)$ of Sample 1 in the pit base marking the center region of the pit (1 mm diameter) where equibiaxial conditions are satisfied. 
Strain evolution at the early stages of the test (Figure 4.10) shows that the entire pit base deforms uniformly until $\varepsilon_{1}=0.06$ and then strain bands start to form as strain approaches $\mathrm{n}$. When $\varepsilon_{1} \approx \mathrm{n}$, the strain bands become sharper.

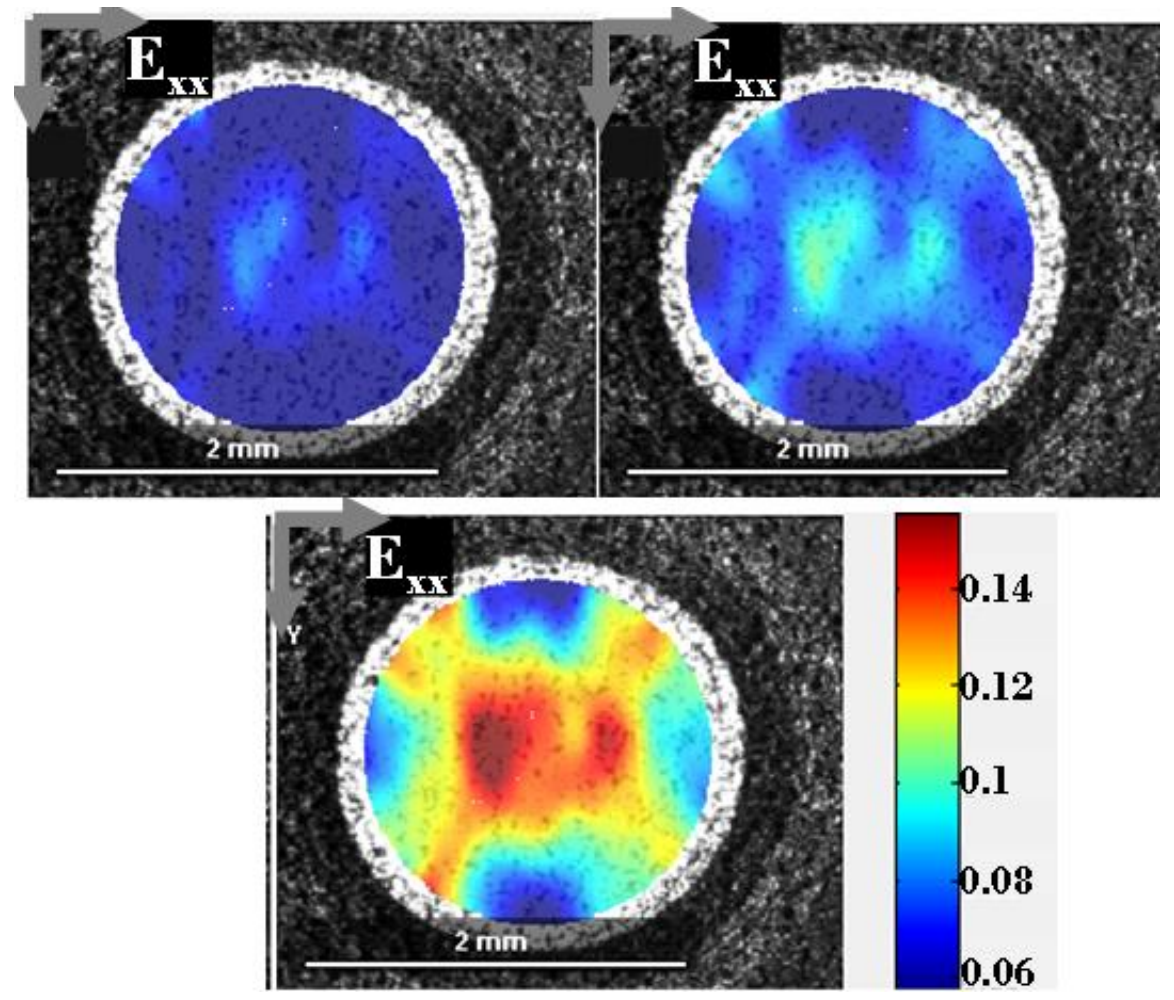

Figure 4.10. $E_{\mathrm{xx}}$ Green-Lagrangian strain results of biaxial test of Sample 1.

In addition to principal strains, bands also accumulate shear strains, which cancel each other at the center (Figure 4.9). As the shear strain should be zero in equibiaxial tension [3], the whole test region does not satisfy the criteria even if the median true strains were balanced. The true equibiaxial condition is achieved at the center within a circular area having $1 \mathrm{~mm}$ diameter (Figure 4.9), where the principal strains are maximum and the shear strains are approximately zero. Median true principal strains in this region are calculated as $\varepsilon_{1}=0.19$ and $\varepsilon_{2}=0.16$, resulting in an equivalent strain $(\bar{\varepsilon})$ of 0.35 . The two intersecting strain bands, therefore, maximize the principal and equivalent strains at the center and promote fracture at the same location. 
In uniaxial tension, necking starts when the strain reaches to the strain hardening exponent (n) due to load instability. Although necking due to load instability is not possible in biaxial tension, local imperfections in the thickness can lead to localized strains and necking [3]. Usually, a single local neck forms perpendicular to the direction of larger principal strain $\left(\varepsilon_{1}\right)$ [3, 62, 63]. In this case, surfaces were machined precisely and there was no significant thickness variation along the surface that would cause imperfections (Figure 4.7). Strain bands are perpendicular to each other but not to either of the principal strains. Then, the strain bands in Figure 4.8 cannot be defined as local necks originating from imperfections. On the other hand, necking was observed at the corners of the sample as if the corners were tested under uniaxial tension (Figure 4.11 (a)). Indeed, the stress state at the corners is also shown to be uniaxial tension and plastic strain accumulation is possible at the corners as they act as stress concentrators $[9,13,50]$. 


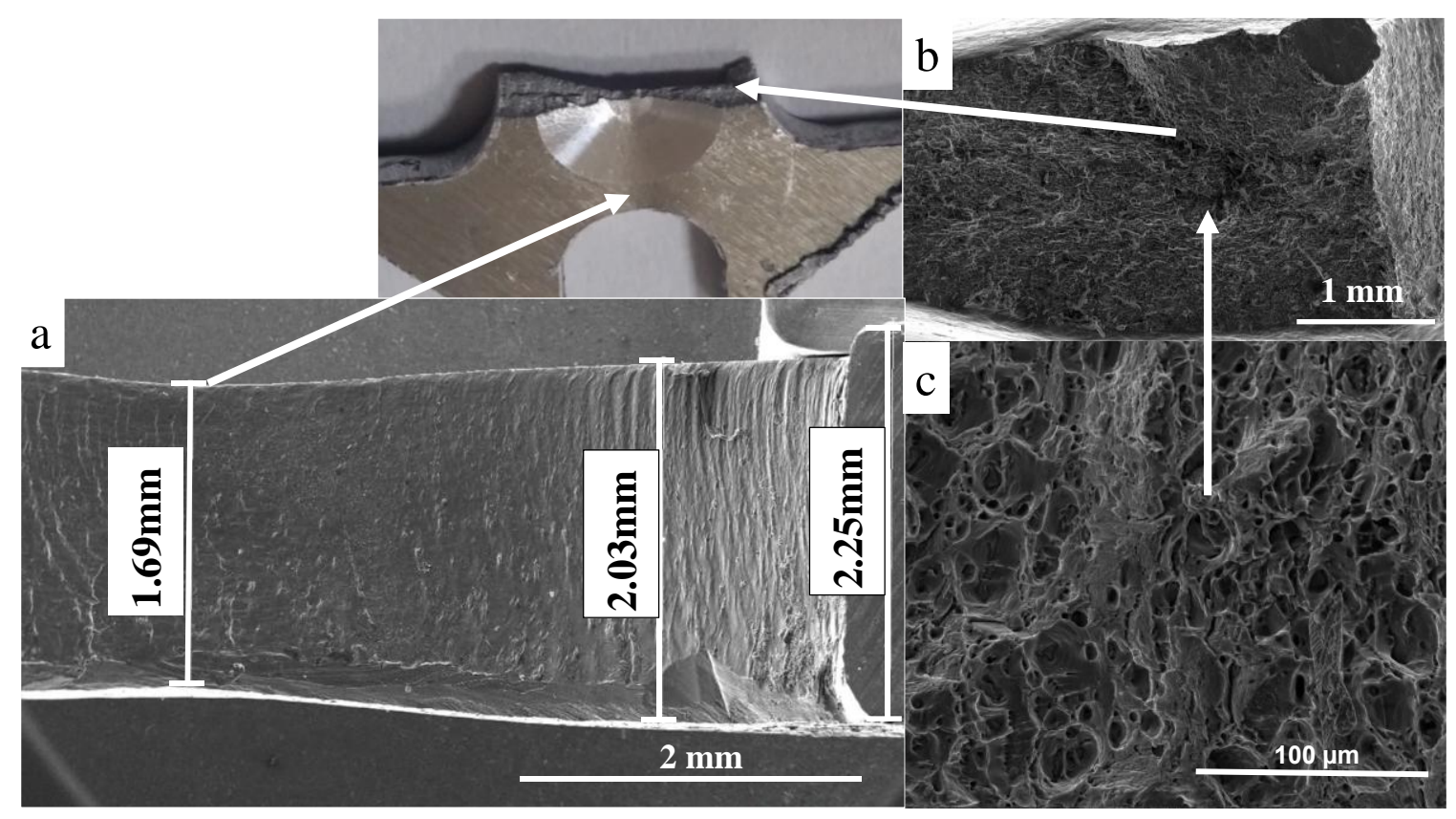

Figure 4.11. SEM images from the fractured sample showing the necking (a) and cup-and-cone type fracture (b) at the corners. (c) SEM image at the 1500X magnification. Ductile fracture is evident in the neck whereas edges show shear-type fracture.

In the test samples, corners collect the second highest equivalent stress (95\% of the pit), and they may be plastically deformed. The fracture surface of the cross-section (Figure 4.11 (b)) does not provide sufficient evidence for the source of the strain bands, but plastic deformation and cup-and-cone type fracture are evident at the corners. High magnification SEM image were given in Figure 4.11 (c).

These observations suggest that strain bands may originate from the corners. Together with the pits, the corners may deform uniformly until the overall strain reaches $n$. After this, necks form at all corners and strain bands connect them. As strain bands intersect each other at the center, this region continues to deform under equibiaxial tension and reaches large equivalent strain, $\bar{\varepsilon}=0.35$. This mechanism 
is schematically depicted in Figure 4.12 (a) and confirmed by the SEM picture in Figure 4.12 (b).

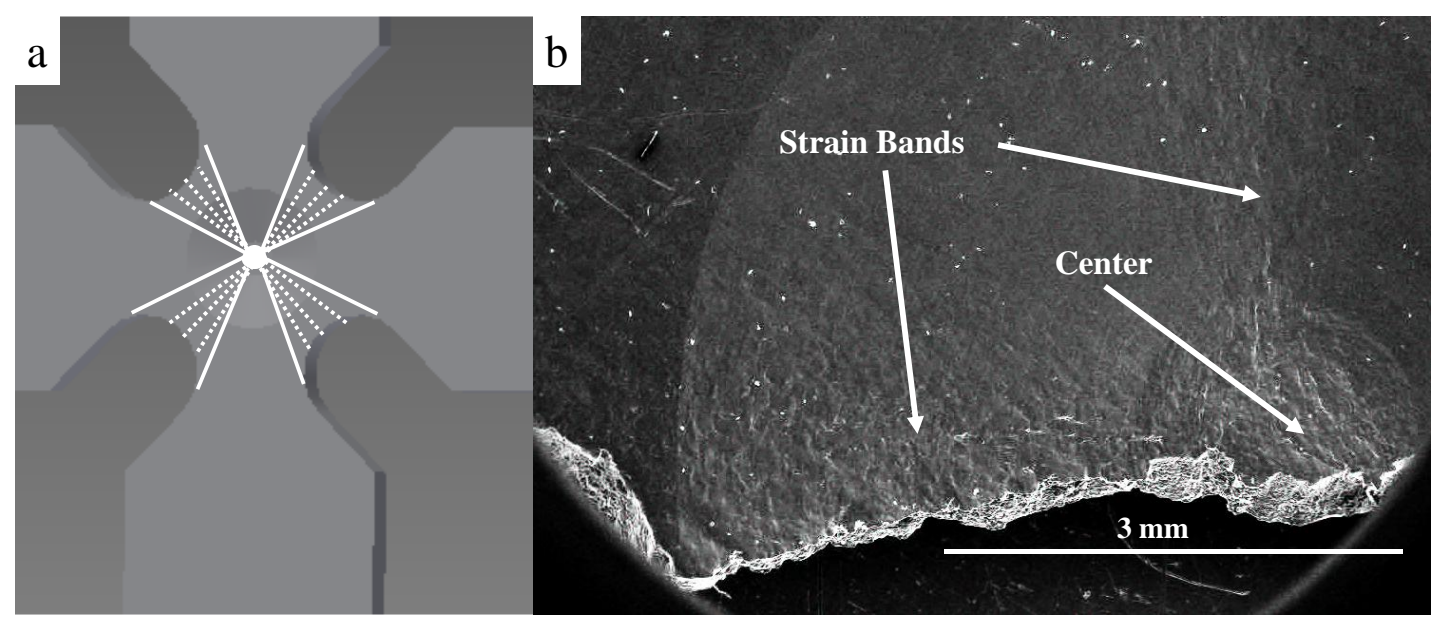

Figure 4.12. Schematic drawing of the sample (a) and SEM images (b) showing the location of the strain bands. Surface protrusions are visible in the strain bands and at the center confirming the plastic deformation of these regions.

Surface protrusions are concentrated in the strain bands and the center, while the rest of the sample remains undeformed. Indeed any cruciform geometry can develop this type of strain distribution, as the stress concentration at the corners is unavoidable. In this case, the strain bands were distinct due to the small-scale of the samples, where the width of the strain bands is nearly equal to the diameter of the pit base $(2 \mathrm{~mm})$.

Local necks in uniaxial tension of sheet are also capable of deforming to large equivalent strains. Figure 4.13 shows the principal strain $\left(E_{1}=E_{y y}\right)$ distribution along the gage length of the tensile test specimen just before fracture. 


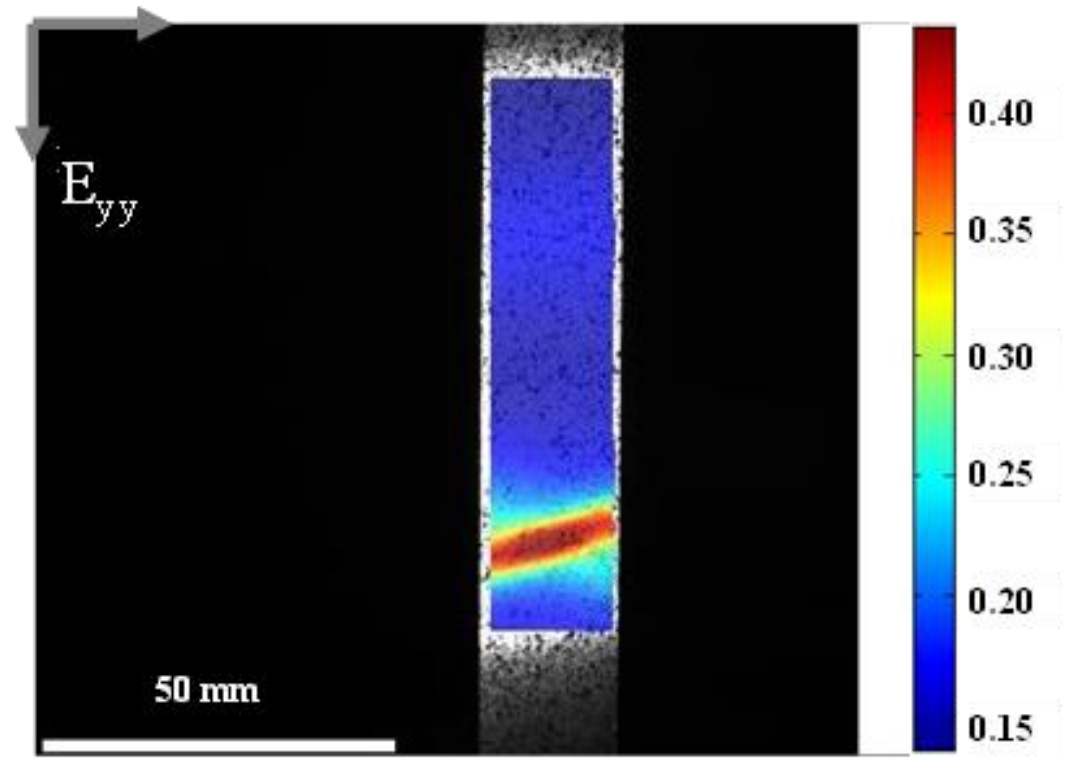

Figure 4.13. Strain map of the principal Green-Lagrangian strain $\left(E_{y y}=E_{1}\right)$ in uniaxial tensile testing of the sheet before fracture. The sharp, tilted local neck common in uniaxial tensile testing is visible in the map.

A sharp, tilted local neck is visible, common to the tensile testing of sheet metals [1-3]. The median strain along the gage length, $\mathrm{E}_{1}=0.16$, is consistent with the engineering strain measured by the optical extensometer (Table 3.1). Regions adjacent to the neck are strained to $\varepsilon_{1}=0.20$, satisfying the $\varepsilon_{1}=2$ n criteria necessary for the onset of localized necking [3]. Assuming $\bar{\varepsilon} \sim \varepsilon_{1}$ in the local neck, the maximum strain material can sustain before fracture is $\bar{\varepsilon}=0.34$. Similar fracture strains in both biaxial and uniaxial tests, confirm that biaxial test is capable of deforming the material until fracture.

Figure 4.14 shows the strain map $\left(\mathrm{E}_{\mathrm{xx}}\right)$ before fracture at the microstructure scale. The map is located at the sample center and contains about 45 grains. Strain distribution is non-uniform and localized to some grains and grain boundaries. Cracks start from the strain localized regions, but they were not included in the analysis. While the distribution is inhomogeneous, the average true principal 
strains of $\varepsilon_{1}=0.18$ and $\varepsilon_{2}=0.17$ and equivalent strain of $\bar{\varepsilon}=0.35$ confirm that the equibiaxial conditions are valid until fracture (Figure 4.8). A higher resolution map (currently 2 subsets/grain) combined with local texture data may explain the localizations and suggest mechanisms for fracture.

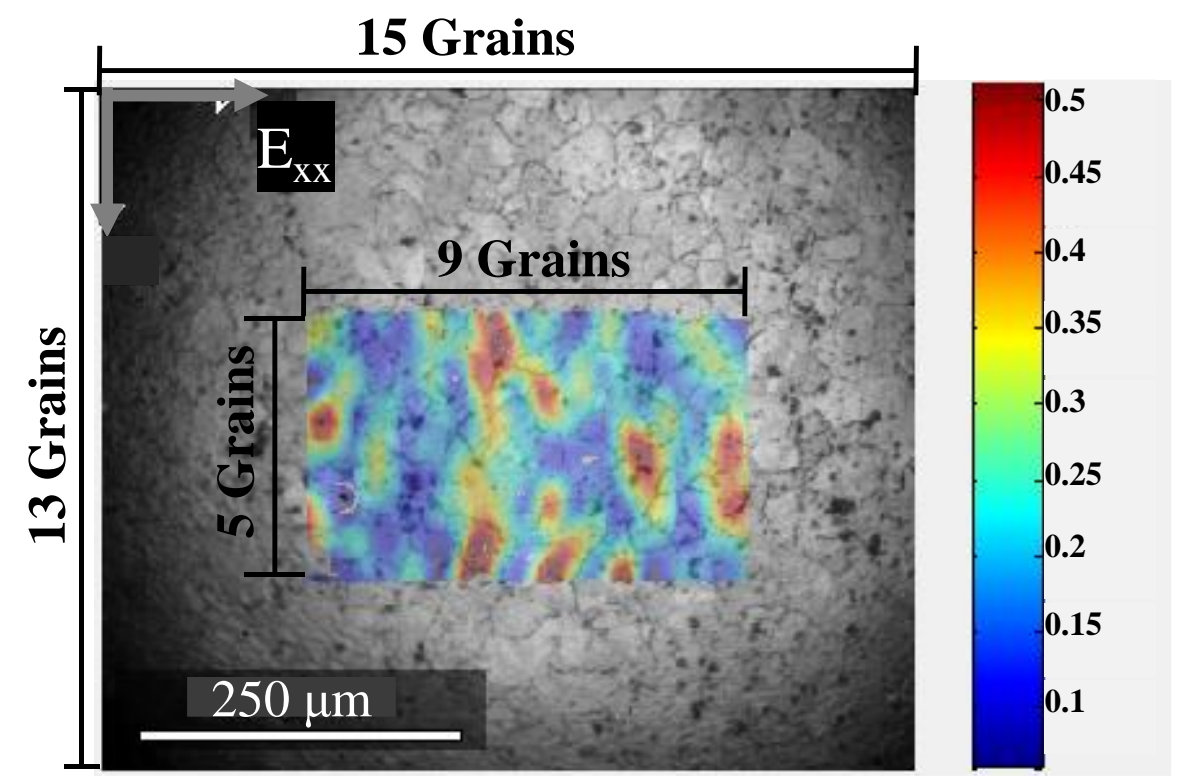

Figure 4.14. Microstructure scale strain map.

\subsection{Comparison with other Multi-Axial Tests}

Forming limit curves (FLC) give the maximum strains that a material can sustain before failure at different stress states. While in theory it is possible to stretch a material to its fracture limits under equibiaxial tension, the mechanism of failure is generally a localized deformation preceding the fracture [3]. The sources of localized deformation are soft spots in the material, since the geometric softening (i.e. load instability) is not possible due the positive principal strains in the righthand side of the FLD. The soft spots in the material, usually in the form of local thickness variations, lead to sharp local necks during the tests, which maximizes the major strain $\left(\varepsilon_{1}\right)$ over the minor strain $\left(\varepsilon_{2}\right)$, i.e. plane-strain conditions. Within 
the neck, the major strain quickly reaches to the fracture limit, preventing material to deform under equibiaxial tension until fracture $[3,62,63]$.

When experimentally determining the FLC, the standard procedure (ISO 12004$2: 2008)[53,61]$ is to smooth out the major strain inside the neck, resulting in approximately equal strains as the limits under biaxial tension [61]. Analytical methods such as Marciniak - Kuczynski analysis (known as the M-K analysis) or numerical methods can also model and simulate the FLC [64, 65]. In FLC modelling, M-K analysis depends heavily on the geometrical imperfection factor $\left(f_{0}\right)$ as the ratio of imperfection thickness to the initial thickness of the deformed sheet, whereas numerical methods rely on localization and damage parameters [3, $63,65]$. As the selection of these parameters alter the limiting strains, both models are usually calibrated with experiments that have the sharp, local neck preceding fracture. Then, the limiting strain obtained from experimental, analytical and numerical models can be smaller than the actual fracture strains [63]. In these tests, the fracture strain of the material can be reached under equibiaxial tension, as the test area was located at the center of two intersecting necks, which prevented a further local neck within the test area. Moreover, precise machining of the surfaces prevented local thickness variations and the source of failure was likely the local variations in the material such as grain size, precipitates and texture.

Strains in FLC are directly proportional to the strain hardening exponent of a given material. For relatively brittle materials, the ratio of principal strains to $n$ is approximately 1 for equibiaxial tension $\left(\varepsilon_{1} / \mathrm{h} \sim 1, \varepsilon_{2} / \mathrm{h} \sim 1\right)$, resulting in $\bar{\varepsilon} / \mathrm{h} \sim 2$ [1]. For more ductile materials, the ratio can be as high as 2 , resulting in $\bar{\varepsilon} / \mathrm{h} \sim 4$ [1]. Figure 4.15 documents the limiting effective strains under equibiaxial condition as a function of $\mathrm{n}$ for various multi-axial tests and materials $[5,9,13,46$, 62, 64, 66-72], including the cruciform test results for Al 6061-T6. Standard procedure was followed for determining the FLC (ISO 12004-2:2008) in results in order to make a fair comparison. 


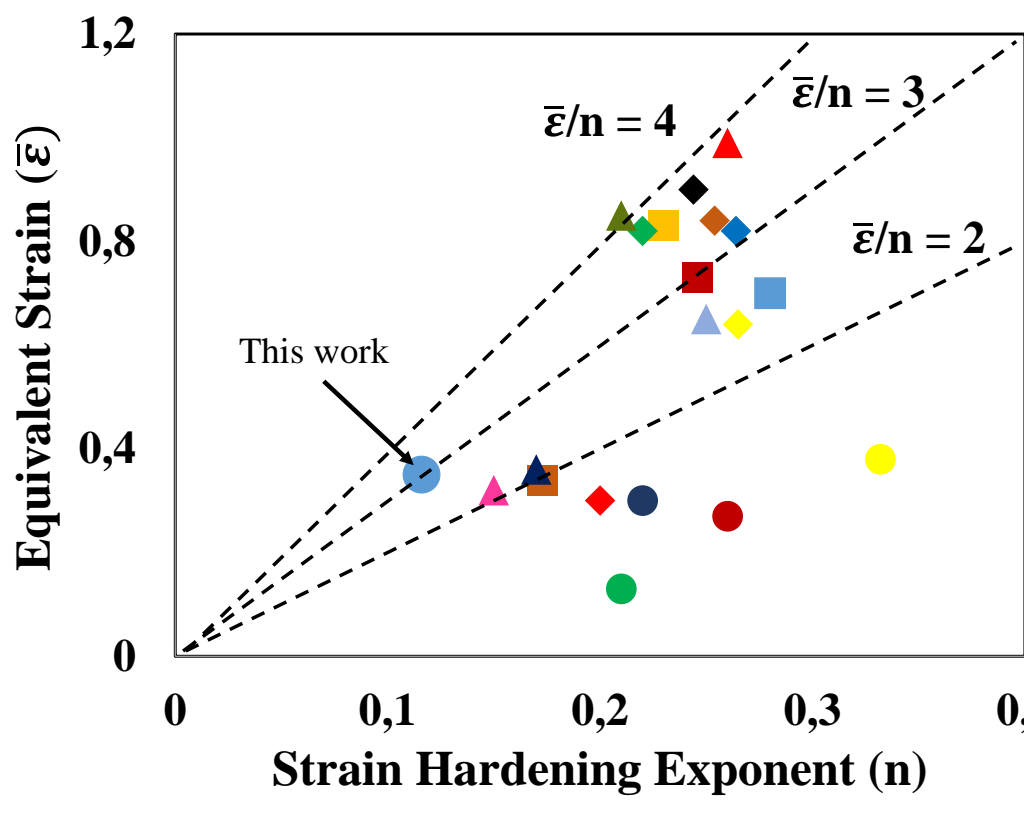

AA 6061 T6 - Cruciform AISI 1008 - Cruciform [15]

- LCS - Cruciform [15]

- AA 1145 - Cruciform [53]

- AA 5086 - Cruciform [9]

FEP 04 - Marciniak [51]

AA 5083 O - Marciniak [56]

- LCS - Marciniak [57]

AA 3003 H16 - Marciniak [58]

- IF Steel - Nakazima [59]

- DP 590 - Nakazima [60]

AA 2024 T4 - Nakazima [49]

- St 1203 - Nakazima [54]

Pure Aluminum - Nakazima [54]

- St 1403 - Nakazima [54]

$\triangle$ AA 6061 T6 - Hyd.Bulge [5]

$\triangle$ Ti6Al4V - Hyd.Bulge [5]

0,4 A AA 1050 O - Hyd.Bulge [55]

$\triangle$ AA 3004 O - Hyd.Bulge [55]

$\triangle$ AA 5052 O - Hyd.Bulge [55]

Figure 4.15. Comparison of the limiting effective strains under equibiaxial condition as a function of $\mathrm{n}$ for various multi-axial tests and materials. The constant ratio lines, $\bar{\varepsilon} / n=4, \bar{\varepsilon} / n=3, \bar{\varepsilon} / n=2$, classify the materials and tests. Our results for $\mathrm{Al} 6061-\mathrm{T} 6(\bar{\varepsilon} / n \sim 3)$ surpass the limiting strains for similar materials tested by cruciform and other standard tests.

Since there are no sharp necks in the tests, it was averaged (smoothened) the principal strains over an area instead of a line that is perpendicular to the neck [63, 65]. The constant ratio lines, $\bar{\varepsilon} / \mathrm{n}=4, \bar{\varepsilon} / \mathrm{n}=3, \bar{\varepsilon} / \mathrm{n}=2$, on the plot classify the materials and tests. As expected, ductile materials tested with hydraulic bulge test reach to the maximum ratio. Cruciform tests in general are unable reach to large strains, even for ductile $\mathrm{Al}$ alloys. While the other test are located around $\bar{\varepsilon} / \mathrm{n} \sim 3$, for ductile materials, and $\bar{\varepsilon} / \mathrm{h} \sim 2$, for brittle materials, the result for the relatively brittle $\mathrm{Al} 6061-\mathrm{T} 6$ is around $\bar{\varepsilon} / \mathrm{n} \sim 3$, signifying the large strain capability of this test. 


\section{CHAPTER 5}

\section{CONCLUSION \& FUTURE RECOMMENDATIONS}

\subsection{Conclusion}

The portable apparatus demonstrated in this study is capable of testing miniature cruciform samples under biaxial stress states. In-situ strain analysis at the microstructure scale was possible with the custom-made microscope and 2D-DIC system integrated to the apparatus. Cruciform designs reported in the literature were scaled down with the help of FEM simulations. Test results showed that the linear FEM simulations of maximum effective stresses were quite successful in predicting the fracture locations of the samples. Initial designs prematurely failed from the edges of the pit that was machined in the samples, leaving the center with reduced thickness undeformed. The small strain and premature fracture problems common to the cruciform tests were solved by optimizing the pit geometry and carefully controlling the manufacturing steps and surface finish. The tapered pit with a flat and smooth base resulted in center fracture and allowed in-plane deformation and 2D-DIC. Strain maps and SEM images of the fractured sample showed two strain bands intersecting at the center. The strain bands started to form at the corners when strain reached $n$, and allowed the center to be deformed under equibiaxial condition without significant shear strains. As the strain bands suppressed the formation of the local necks, the effective strain at the center reached to the fracture strain of the material. 
Comparison of the results with uniaxial tension and other multi-axial tests confirmed the large strain capability of this cruciform test. The effective strain under equibiaxial condition $(\bar{\varepsilon}=0.35)$ coincided with the strain inside the local neck observed in uniaxial tensile testing of the sheet. When normalized by the strain hardening exponent of Al 6061-T6, the effective strain, $\bar{\varepsilon} / \mathrm{n} \sim 3$, was significantly higher than the cruciform test results reported in the literature. This value even surpassed the results of other standard tests (e.g. Nakazima, Marciniak) for similar materials $(\bar{\varepsilon} / \mathrm{h} \sim 2)$.

Lack of local necking in the cruciform test permits uniform deformation until fracture. This will allow the observation of true material behavior and the microstructure related failure mechanisms under biaxial stress states. Unlike the uniaxial tests, cruciform test will give the strain path dependence of the deformation and fracture behavior. Strain maps at the small-scale can be linked to microstructural features in order to explain the sources of localized deformation and fracture. Strain maps combined with the stress data can also give the global mechanical properties of the material, such as the strain hardening law under large strains.

\subsection{Future Recommendations}

Lightweight materials and advanced steels may require warm forming at high deformation rates and their micromechanical behavior strongly depends on their microstructural features. As an alternative to small-scale testing in SEM, high temperature and high strain rate tests are possible with this setup. Mechanical behavior data collected at these thermo-mechanical conditions and microstructure scale will be critical for the constitutive models necessary for the simulation of industrial forming processes. 


\section{REFERENCES}

1. Hosford, W.F. and R.M. Caddell, Metal Forming (Mechanics and Metallurgy). 1993, New York: Cambridge University Press.

2. Hannon, A. and P. Tiernan, A review of planar biaxial tensile test systems for sheet metal. Journal of Materials Processing Technology, 2008. 198(1-3): pp. 1-13.

3. Marciniak, Z., J.L. Duncan, and S.J.Hu, Mechanics of Sheet Metal Forming. 1992, London: Edward Arnold.

4. Tong, W., Strain characterization of propagative deformation bands. . Journal of the Mechanics and Physics of Solids, 1998. 46: pp. 2087-2102.

5. Djavanroodi, F. and A. Derogar, Experimental and numerical evaluation of forming limit diagram for Ti6Al4V titanium and Al6061-T6 aluminum alloys sheets. Materials \& Design, 2010. 31(10): pp. 4866-4875.

6. Kang, J., et al., Digital image correlation studies for microscopic strain distribution and damage in dual phase steels. . Scripta Materialia, 2007. 56: pp. 999-1002.

7. Efstathiou, C., H. Sehitoglu, and J. Lambros, Multiscale strain measurements of plastically deforming polycrystalline titanium: Role of deformation heterogeneities. International Journal of Plasticity, 2010. 26: pp. 93-106.

8. Mattei, L., et al., Strain localization and damage mechanisms during bending of AA6016 sheet. . Materials Science and Engineering A, 2013. 559: pp. 812-821.

9. Liu, W., et al., Identification of sheet metal hardening for large strains with an inplane biaxial tensile test and a dedicated cross specimen. International Journal of Mechanical Sciences, 2015. 101-102: pp. 387-398.

10. Kleiner, M., M. Geiger, and A. Klaus, Manufacturing of Lightweight Components by Metal Forming. . CIIRP Annals - Manufacturing Technology, 2003. 52: pp. 521-542. 
11. Pattaky, G. and H. Sehitoglu, Experimental Methodology for Studying Strain Heterogeneity with Microstructural Data from High Temperature Deformation. Experimental Mechanics, 2015. 55: pp. 53-65.

12. Dawicke, D. and W. Pollock, Biaxial testing of 2219-T87 aluminum alloy using cruciform specimens. 1997: National Aeronautics and Administration, Langley Research Center.

13. Banerjee, D., et al. An Experimental and Numerical Study of Deformation Behavior of Steels in Biaxial Tensile Tests. Conference Tools for 2015 TMS Annual Meeting \& Exhibition. 2015.

14. Deng, N., T. Kuwabara, and Y.P. Korkolis, Cruciform Specimen Design and Verification for Constitutive Identification of Anisotropic Sheets. Experimental Mechanics, 2015. 55(6): pp. 1005-1022.

15. Merklein, M. and M. Biasutti, Development of a biaxial tensile machine for characterization of sheet metals. Journal of Materials Processing Technology, 2013. 213(6): pp. 939-946.

16. Mitukiewicz, G. and M. Głogowski, Cruciform specimen to obtain higher plastic deformation in a gauge region. Journal of Materials Processing Technology, 2016. 227: pp. 11-15.

17. Collins, D.M., et al., A synchrotron X-ray diffraction study of in situ biaxial deformation. Acta Materialia, 2015. 90: pp. 46-58.

18. Parts, C.B. [cited 2016 05.06]; Available from: http://aluminium.matter.org.uk/.

19. Magnesium Sets a New Protection Standard: Durability, Strength and CuttingEdge Style. , in Mg Showcase. 2007, International Magnesium Association.

20. Ghiotti, A., S. Bruschi, and P.F. Bariani, Determination of yield locus of sheet metal at elevated temperatures: a novel concept for experimental set-up. Key Engineering Materials, 2007. 344: pp. 97-104.

21. Keeler, S. and M. Kimchi, Advanced High-Strength Steels Application Guidelines Version 5.0, W.A. Steel, Editor. 2014.

22. Matlock, K.D. and G.J. Speer, Third Generation of AHSS: Microstructure Design Concepts, in Microstructure and Texture in Steels: and Other Materials, A. 
Haldar, S. Suwas, and D. Bhattacharjee, Editors. 2009, Springer London: London. pp. 185-205.

23. Shi, Y., et al., Analysis of Surface Roughening in AA6111 Automotive Sheet Under Pure Bending. Metallurgical and Materials Transactions A, 2016. 47(2): pp. 949960.

24. Raabe, D., et al., Grain-scale micromechanics of polycrystal surfaces during plastic straining. Acta Materialia, 2003. 51.

25. Ghassemieh, E., Materials in Automotive application, State of the Art and Prospects. In: Chiaberge M, editor. New Trends and Developments in Automotive Industry: InTech. 2011: pp. 94-365.

26. Banabic, D., Sheet Metal Forming Processes. 2009: Springer.

27. Swift, H.W., Plastic instability under plane stress. Journal of the Mechanics and Physics of Solids, 1952. 1(1): pp. 1-18.

28. Hill, R., On discontinuous plastic states, with special reference to localized necking in thin sheets. Journal of the Mechanics and Physics of Solids, 1952. 1(1): pp. 19-30.

29. Marciniak, Z. and K. Kuczyński, Limit strains in the processes of stretch-forming sheet metal. International Journal of Mechanical Sciences, 1967. 9(9): pp. 609620.

30. Liu, J., M. Ahmetoglu, and T. Altan, Evaluation of sheet metal formability, viscous pressure forming (VPF) dome test. Journal of Materials Processing Technology, 2000. 98(1): pp. 1-6.

31. Gutscher, G., et al., Determination of flow stress for sheet metal forming using the viscous pressure bulge (VPB) test. Journal of Materials Processing Technology, 2004. 146(1): pp. 1-7.

32. Banabic, D., et al., Development of a new procedure for the experimental determination of the Forming Limit Curves. CIRP Annals - Manufacturing Technology, 2013. 62(1): pp. 255-258. 
33. Tasan, C., et al. In-Plane Biaxial Loading of Sheet Metal until Fracure. in SEM XI International Congress \& Exposition on Experimental \& Applied Mechanics. 2008. Florida USA: Experimental Mechanics.

34. Demeri, M.Y., Advanced High-Strength Steels. Science, Technology and Applications. 2013, Ohio: ASM International.

35. Ozturk, F. and D. Lee, Experimental and numerical analysis of out-of-plane formability test. Journal of Materials Processing Technology, 2005. 170(1-2): pp. 247-253.

36. Iadicola, M., et al. Marciniak Multiaxial Testing. 2014 [cited 2016 24.05]; Available from: www.nist.gov/lightweighting/.

37. Tasan, C.C., et al., Multi-Axial Deformation Setup for Microscopic Testing of Sheet Metal to Fracture. Experimental Mechanics, 2011. 52(7): pp. 669-678.

38. Raghavan, K.S., A simple technique to generate in-plane forming limit curves and selected applications. Metallurgical and Materials Transactions A, 1995. 26(8): pp. 2075-2084.

39. Tasan, C.C., J.P.M. Hoefnagels, and M.G.D. Geers, Identification of the continuum damage parameter: An experimental challenge in modeling damage evolution. Acta Materialia, 2012. 60(8): pp. 3581-3589.

40. Walley, J.L., et al., In-Situ Mechanical Testing for Characterizing Strain Localization During Deformation at Elevated Temperatures. Experimental Mechanics, 2011. 52(4): pp. 405-416.

41. Kuwabara, T., S. Ikeda, and T. Kuroda, Measurement and Analysis of Differential Work Hardening in Cold-Rolled Steel Sheet under Biaxial Tension. Journal of Materials Processing Technology., 1998. 80/81: pp. 517-523.

42. Garcia, D., J.J. Orteu, and L. Penazzi, A combined temporal tracking and stereocorrelation technique for accurate measurement of $3 D$ displacements: application to sheet metal forming. Journal of Materials Processing Technology, 2002. 125126(0): pp. 736-742. 
43. Efstathiou, C., H. Sehitoglu, and J. Lambros, Multiscale strain measurements of plastically deforming polycrystalline titanium: Role of deformation heterogeneities. International Journal of Plasticity, 2010. 26(1): pp. 93-106.

44. Tekkaya, A.E., State-of-the-art of simulation of sheet metal forming. Journal of Materials Processing Technology, 2000. 103(1): pp. 14-22.

45. Abu-Farha, F., L.G. Hector, and M. Khraisheh, Cruciform-shaped specimens for elevated temperature biaxial testing of lightweight materials. JOM. Vol. 61. 2009. 48-56.

46. Green, D.E., et al., Experimental investigation of the biaxial behaviour of an aluminum sheet. International Journal of Plasticity, 2004. 20(8-9): pp. 1677-1706.

47. Zidane, I., et al., Development of an in-plane biaxial test for forming limit curve (FLC) characterization of metallic sheets. Measurement Science and Technology, 2010. 21.

48. Nagayasu, T., S. Takahashi, and T. Kuwabara, Development of compact biaxial tensile testing apparatus using conventional compression testing machine and evaluation of the test results., in Biennal Congresses and Conferences. 2010, IDDRG Papers.

49. Guelho, I., et al., Optimization of cruciform specimen for a low capacity biaxial testing machines, in 10th Int. Conf. Multiaxial Fatigue Fracture. 2013.

50. Iadicola, M., A. Creuziger, and T. Foecke, Advanced Biaxial Cruciform Testing at the NIST Center for Automotive Lightweighting, in Residual Stress, Thermomechanics \& Infrared Imaging, Hybrid Techniques and Inverse Problems, Volume 8, M. Rossi, et al., Editors. 2014, Springer International Publishing. pp. 277-285.

51. Müller, W. and K. Pöhlandt, New experiments for determining yield loci of sheet metal. Journal of Materials Processing Technology, 1996. 60(1-4): pp. 643-648.

52. Geiger, M., W. Hußnätter, and M. Merklein, Specimen for a novel concept of the biaxial tension test. Journal of Materials Processing Technology, 2005. 167(2-3): pp. $177-183$. 
53. Bing, P., et al., Two-dimensional digital image correlation for in-plane displacement and strain measurement: a review. Measurement Science and Technology, 2009. 20(6): pp. 062001.

54. Rechenmacher, A.L., Grain-scale processes governing shear band initiation and evolution in sands. Journal of the Mechanics and Physics of Solids, 2006. 54(1): pp. 22-45.

55. Moerman, K.M., et al., Digital image correlation and finite element modelling as a method to determine mechanical properties of human soft tissue in vivo. Journal of Biomechanics, 2009. 42(8): pp. 1150-1153.

56. Ahmed, W.W., M.H. Kural, and T.A. Saif, A novel platform for in situ investigation of cells and tissues under mechanical strain. Acta Biomaterialia, 2010. 6(8): pp. 2979-2990.

57. Master, S. LaVision. [cited 2016 05.06]; Available from: http://www.lavision.de/en/techniques/digital-image-correlation.php.

58. Blaber, J., B. Adair, and A. Antoniou, Ncorr: Open-Source 2D Digital Image Correlation Matlab Software. Experimental Mechanics, 2015. 55(6): pp. 11051122.

59. Blaber, J. Open Source 2D-DIC MATLAB Software. Ncorr V1.2. [cited 2016 27.01]; Available from: http://ncorr.com/.

60. Marya, M., et al., Microstructural effects of AZ31 magnesium alloy on its tensile deformation and failure behaviors. Materials Science and Engineering A, 2006. 418: pp. 341-356.

61. Sowerby, R., E. Chu, and J.L. Duncan, Determination of large strains in metalforming. The Journal of Strain Analysis for Engineering Design, 1982. 17(2): pp. 95-101.

62. Dilmec, M., et al., Detailed Investigation of Forming Limit Determination Standards for Aluminum Alloys. . Journal of Testing Evaluation, 2013. 41.

63. Vysochinskiy, D., et al., Experimental detection of forming limit strains on samples with multiple local necks. Journal of Materials Processing Technology, 2016. 227: pp. 216-226. 
64. Brunet, M., S. Mguil, and F. Morestin, Analytical and experimental studies of necking in sheet metal forming processes. Journal of Materials Processing Technology, 1998. 80-81: pp. 40-46.

65. Brunet, M. and F. Morestin, Experimental and analytical necking studies of anisotropic sheet metals. Journal of Materials Processing Technology, 2001. 112(2-3): pp. 214-226.

66. Stachowicz, F., Effects of microstructure on the mechanical properties and limit strains in uniaxial and biaxial stretching. Journal of Mechanical Working Technology, 1989. 19(3): pp. 305-317.

67. Kohara, S., Special Issue on Aluminium FormingForming-limit curves of aluminum and aluminum alloy sheets and effects of strain path on the curves. Journal of Materials Processing Technology, 1993. 38(4): pp. 723-735.

68. Naka, T., et al., The effects of temperature and forming speed on the forming limit diagram for type 5083 aluminum-magnesium alloy sheet. Journal of Materials Processing Technology, 2001. 113(1-3): pp. 648-653.

69. Ahmadi, S., A.R. Eivani, and A. Akbarzadeh, Experimental and analytical studies on the prediction of forming limit diagrams. Computational Materials Science, 2009. 44(4): pp. 1252-1257.

70. Ahmadi, S., A. Eivani, and A. Akbarzadeh, An experimental and theoretical study on the prediction of forming limit diagrams using new BBC yield criteria and $M$ K analysis. . Computational Materials Science, 2009. 44: pp. 1272-1280.

71. Ávila, A.F. and E.L.S. Vieira, Proposing a better forming limit diagram prediction: a comparative study. Journal of Materials Processing Technology, 2003. 141(1): pp. 101-108.

72. Kim, S.B., et al., Forming limit diagram of auto-body steel sheets for high-speed sheet metal forming. Journal of Materials Processing Technology, 2011. 211(5): pp. 851-862. 


\section{SPRINGER LICENSE TERMS AND CONDITIONS}

Jul 17, 2016

This Agreement between yadigar seymen ("You") and Springer ("Springer") consists of your license details and the terms and conditions provided by Springer and Copyright Clearance Center.

License Number

3902670556946

License date Jul 05, 2016

Licensed Content Publisher Springer

Licensed Content Experimental Mechanics

Publication

Licensed Content Title Large Strain and Small-Scale Biaxial Testing of Sheet Metals

Licensed Content Author Y. Seymen

Licensed Content Date Jan 1, 2016

Type of Use Thesis/Dissertation

Portion $\quad$ Full text

Number of copies 6

Author of this Springer $\quad$ Yes and you are the sole author of the new work

article

Order reference number

Title of your thesis / $\quad$ Large Strain and Small-Scale Biaxial Testing of Sheet Metals dissertation

Expected completion date Jul 2016

Estimated size(pages) $\quad 55$ 


$\begin{array}{ll}\text { Requestor Location } & \begin{array}{l}\text { yadigar seymen } \\ \text { Middle East Technical University }\end{array} \\ & \\ & \text { ankara, 06800 } \\ & \text { Turkey } \\ & \text { Attn: yadigar seymen } \\ \text { Billing Type } & \text { Invoice } \\ \text { Billing Address } & \text { yadigar seymen } \\ & \text { Middle East Technical University }\end{array}$

ankara, Turkey 06800

Attn: yadigar seymen

Total $\quad 0.00$ USD

Terms and Conditions

\section{Introduction}

The publisher for this copyrighted material is Springer. By clicking "accept" in connection with completing this licensing transaction, you agree that the following terms and conditions apply to this transaction (along with the Billing and Payment terms and conditions established by Copyright Clearance Center, Inc. ("CCC"), at the time that you opened your Rightslink account and that are available at any time at http://myaccount.copyright.com).

Limited License

With reference to your request to reuse material on which Springer controls the copyright, permission is granted for the use indicated in your enquiry under the following conditions: 
- Licenses are for one-time use only with a maximum distribution equal to the number stated in your request.

- Springer material represents original material which does not carry references to other sources. If the material in question appears with a credit to another source, this permission is not valid and authorization has to be obtained from the original copyright holder.

- This permission

- is non-exclusive

- is only valid if no personal rights, trademarks, or competitive products are infringed.

- explicitly excludes the right for derivatives.

- Springer does not supply original artwork or content.

- According to the format which you have selected, the following conditions apply accordingly:

- Print and Electronic: This License include use in electronic form provided it is password protected, on intranet, or CD-Rom/DVD or E-book/E-journal. It may not be republished in electronic open access.

-Print: This License excludes use in electronic form.

-Electronic: This License only pertains to use in electronic form provided it is password protected, on intranet, or CD-Rom/DVD or E-book/E-journal. It may not be republished in electronic open access. For any electronic use not mentioned, please contact Springer at permissions.springer@spi-global.com.

- Although Springer controls the copyright to the material and is entitled to negotiate on rights, this license is only valid subject to courtesy information to the author (address is given in the article/chapter).

- If you are an STM Signatory or your work will be published by an STM Signatory and you are requesting to reuse figures/tables/illustrations or single text extracts, permission is granted according to STM Permissions Guidelines: http://www.stmassoc.org/permissions-guidelines/

For any electronic use not mentioned in the Guidelines, please contact Springer atpermissions.springer@spi-global.com. If you request to reuse more content than 
stipulated in the STM Permissions Guidelines, you will be charged a permission fee for the excess content.

Permission is valid upon payment of the fee as indicated in the licensing process. If permission is granted free of charge on this occasion, that does not prejudice any rights we might have to charge for reproduction of our copyrighted material in the future.

-If your request is for reuse in a Thesis, permission is granted free of charge under the following conditions:

This license is valid for one-time use only for the purpose of defending your thesis and with a maximum of 100 extra copies in paper. If the thesis is going to be published, permission needs to be reobtained.

- includes use in an electronic form, provided it is an author-created version of the thesis on his/her own website and his/her university's repository, including UMI (according to the definition on the Sherpa website: http://www.sherpa.ac.uk/romeo/); - is subject to courtesy information to the co-author or corresponding author.

Geographic Rights: Scope Licenses may be exercised anywhere in the world.

Altering/Modifying Material: Not Permitted

Figures, tables, and illustrations may be altered minimally to serve your work. You may not alter or modify text in any manner. Abbreviations, additions, deletions and/or any other alterations shall be made only with prior written authorization of the author(s). Reservation of Rights

Springer reserves all rights not specifically granted in the combination of (i) the license details provided by you and accepted in the course of this licensing transaction and (ii) these terms and conditions and (iii) CCC's Billing and Payment terms and conditions. License Contingent on Payment

While you may exercise the rights licensed immediately upon issuance of the license at the end of the licensing process for the transaction, provided that you have disclosed complete and accurate details of your proposed use, no license is finally effective unless and until full payment is received from you (either by Springer or by CCC) as provided in CCC's Billing and Payment terms and conditions. If full payment is not received by the date due, then any license preliminarily granted shall be deemed automatically revoked 
and shall be void as if never granted. Further, in the event that you breach any of these terms and conditions or any of CCC's Billing and Payment terms and conditions, the license is automatically revoked and shall be void as if never granted. Use of materials as described in a revoked license, as well as any use of the materials beyond the scope of an unrevoked license, may constitute copyright infringement and Springer reserves the right to take any and all action to protect its copyright in the materials.

Copyright Notice: Disclaimer

You must include the following copyright and permission notice in connection with any reproduction of the licensed material:

"Springer book/journal title, chapter/article title, volume, year of publication, page, name(s) of author(s), (original copyright notice as given in the publication in which the material was originally published) "With permission of Springer" In case of use of a graph or illustration, the caption of the graph or illustration must be included, as it is indicated in the original publication.

Warranties: None

Springer makes no representations or warranties with respect to the licensed material and adopts on its own behalf the limitations and disclaimers established by $\mathrm{CCC}$ on its behalf in its Billing and Payment terms and conditions for this licensing transaction.

Indemnity

You hereby indemnify and agree to hold harmless Springer and CCC, and their respective officers, directors, employees and agents, from and against any and all claims arising out of your use of the licensed material other than as specifically authorized pursuant to this license.

No Transfer of License

This license is personal to you and may not be sublicensed, assigned, or transferred by you without Springer's written permission.

\section{No Amendment Except in Writing}

This license may not be amended except in a writing signed by both parties (or, in the case of Springer, by CCC on Springer's behalf. 


\section{Objection to Contrary Terms}

Springer hereby objects to any terms contained in any purchase order, acknowledgment, check endorsement or other writing prepared by you, which terms are inconsistent with these terms and conditions or CCC's Billing and Payment terms and conditions. These terms and conditions, together with CCC's Billing and Payment terms and conditions (which are incorporated herein), comprise the entire agreement between you and Springer (and CCC) concerning this licensing transaction. In the event of any conflict between your obligations established by these terms and conditions and those established by CCC's Billing and Payment terms and conditions, these terms and conditions shall control.

Jurisdiction

All disputes that may arise in connection with this present License, or the breach thereof, shall be settled exclusively by arbitration, to be held in the Federal Republic of Germany, in accordance with German law.

\section{Other conditions:}

V 12AUG2015 